\title{
Impacts of Double V-Rings in the Heat Exchanger Duct on Heat Transfer and Flow Behaviors: A Numerical Study
}

\author{
Amnart Boonloi ${ }^{1}{ }^{1}$ and Withada Jedsadaratanachai $\mathbb{D i D}^{2}$ \\ ${ }^{1}$ Department of Mechanical Engineering Technology, College of Industrial Technology, \\ King Mongkut's University of Technology North Bangkok, Bangkok 10800, Thailand \\ ${ }^{2}$ Department of Mechanical Engineering, School of Engineering, King Mongkut's Institute of Technology Ladkrabang, \\ Bangkok 10520, Thailand \\ Correspondence should be addressed to Withada Jedsadaratanachai; withada.je@kmitl.ac.th
}

Received 22 April 2021; Revised 12 July 2021; Accepted 15 September 2021; Published 7 October 2021

Academic Editor: Mostafa S. Shadloo

Copyright ( 2021 Amnart Boonloi and Withada Jedsadaratanachai. This is an open access article distributed under the Creative Commons Attribution License, which permits unrestricted use, distribution, and reproduction in any medium, provided the original work is properly cited.

\begin{abstract}
The impacts of the double V-rings (DVR) in the heat exchanger duct (HED) on heat transfer and flow structures are numerically analyzed. The general configuration of the DVR is called "type I," while the discrete DVR can be split into two structures, which are called "types II and III." The influences of the DVR sizes, DVR types and flow directions on heat transfer rate, friction loss, and thermohydraulic performance are considered. The Reynolds numbers in the range around 100-2000 (laminar regime at the entrance condition) are selected for the present investigation. The numerical problem of the HED installed with the DVR is solved with the finite volume method (a commercial code). The flow structure, heat transfer mechanism, and performance analysis in the HED that fitted the DVR are reported. The flow and heat transfer profiles in the HED fitted with the DVR are an important knowledge to develop the thermohydraulic performance of compact heat exchangers. As the numerical results, it is seen that the heat transfer ability of the tested duct improves around 1.05-16.62 times upper than the smooth duct. Additionally, the greatest value of the thermal enhancement factor in the HED fitted with the DVR is seen to be around 4.17 at $a / H=0.025, b / H=0.10$, $\operatorname{Re}=2000$, and V-upstream direction for the type I.
\end{abstract}

\section{Introduction}

Thermal performance development and heat transfer rate improvement of heat exchangers in many industries and production processes are important methods for energy conservation of the world. The thermal performance development in the heating/cooling processes can be done by both active and passive methods. The active method is an addition of external power such as vibration into the heating/cooling systems to increase the heat transfer potentiality. Although the active method has high efficiency to augment the heat transfer potentiality, the operation and energy cost may also extremely enhance. The passive method is an installation of vortex generators or turbulators into the heat exchangers to change a general flow structure. The vortex flows and impinging flows are detected when the vortex generators in the heat exchanger systems are installed. The variations of the flow structures disturb thermal boundary layer on heat transfer region that is a key cause for the heat transfer improvement. There are various kinds of the vortex generators such as rib, baffle, winglet, and conical ring. The vortex generator selection for the heating/cooling systems depends on the application of the heat exchangers. In almost cases, the passive technique can maintain the operation cost of the production processes. Therefore, the cost for the thermal development with the passive method is obviously lower than that of the active methods.

The flow and heat transfer analysis in the heat exchangers can be done by both experimental and numerical investigations. The experimental study is an examination with experimental devices. The experimental results from validated system have high reliance and preciseness. 
However, the operation cost for the experimental investigation is extremely high. Moreover, in almost all cases, the experimental results cannot explain the features of flow and heat transfer in the heat exchangers. The numerical investigation is a study of heat transfer and flow profiles with computer programs. The numerical model of the heat transfer systems will be created and solved with the programs. The heat exchanger models must be validated to confirm the reliability of the numerical results. The validations of the numerical model can be done compared with experimental results and correlation values. The numerical study can save the studied cost when compared with the experimental investigation. The description of the heat transfer and flow topologies can be reported from the numerical investigation. The knowledge about flow and heat transfer features in the heat exchanger systems is significant data for the growth of the heat exchanger efficiency.

The examples for the thermal performance development in various heating/cooling processes with the passive method are illustrated as follows. Bahiraei et al. [1] examined the growth of heat transfer potentiality in a square section fitted with $\mathrm{V}$-shaped ribs combining with nanofluid. The influences of the $45^{\circ} \mathrm{V}$-shaped rib on the heat transfer potentiality, friction loss, and thermohydraulic performance were compared with the $60^{\circ} \mathrm{V}$-shaped rib. They presented that the lower entropy generation is found at the $45^{\circ} \mathrm{V}$-shaped rib. They also claimed that the larger rib height with the smaller pitch spacing provides the depressed exergy destruction and extends the higher second law efficiency. Bahiraei et al. [2] numerically investigated the thermohydraulic performance of $\mathrm{Cu}$-water nanofluid in a square duct installed with $90^{\circ}$ $\mathrm{V}$-shaped ribs. The influences of rib parameters, rib heights and rib pitches, were considered. They concluded that the heat transfer rate increases about $28.3 \%$ when enhancing rib height from 2.5 to $7.5 \mathrm{~mm}$ at the pitch spacing of $50 \mathrm{~mm}$. A direct simulation of the entry region heat transfer for a channel installed with ribs at $\mathrm{Re}=20,460$ was reported by Matsubara et al. [3]. They found that the disturbed thermal boundary layer affects the increment of the heat transfer rate at the entry ribbed channel. Li et al. [4] investigated the heat transfer potentiality and flow feature in a microchannel with solid and porous ribs. They found that the thermal performance in the microchannel installed with the rib is greater than the general tested section with no rib. Bahiraei et al. [5] presented the second law analysis for nanofluid in a channel fitted with conical ribs. The effects of rib arrangements and nanoparticle shapes were considered. Jiang et al. [6] illustrated the fluid flow and heat transfer patterns of two-phase flow in a rectangular tested section with column-row-ribs. Bai et al. [7] investigated the rib disturbed entry effect in a pin-fin array for $\mathrm{Re}=7000-40,000$. The effects of rib configurations, $60^{\circ} \mathrm{rib}$, $\mathrm{V}$-shaped and $\mathrm{W}$-shaped ribs, were compared. They found that the entry effect not only develops the heat transfer potentiality, but also relieves the pressure loss. Li et al. [8] studied the pressure drop and heat transfer potentiality in a channel with miniature structured ribs on one wall for $\operatorname{Re}=10,000-60,000$ (turbulent regime) by both numerical and experimental investigations. Their results revealed that the averaged Nusselt number and overall Nusselt number are greater than the smooth channel with no rib around 2.2-2.6 and 2.9-3.3 times, respectively. Bai et al. [9] simulated the pressure loss and heat transfer ability in a pin-fin array installed with ribs. They summarized that the rib induces the secondary flow, which is a reason for heat transfer enhancement. They also informed that the $90^{\circ} \mathrm{rib}$ lets the greatest overall performance. Zhang et al. [10] opted micro-Vshaped ribs and dimples to increase heat transfer coefficient in a channel. Xiao et al. [11] investigated the augmented heat transfer in a minichannel heat sink with $\mathrm{V}$-ribs for $\mathrm{Re}=3600-6800$. Their simulated results revealed that the enhanced heat transfer is around $171-355 \%$ when compared with the general channel. Jain and Lanjewar [12] showed that the maximum enhanced heat transfer in a solar air heater inserted with V-ribs is around 2.30 times above the base case. Jin et al. [13] numerically studied the augmented heat transfer of a solar air heater with multiple-shaped ribs.

In the present investigation, the passive method is selected to extend the heat transfer potentiality of the heat exchanger duct (HED). As the previous works [14-19], we found that the $\mathrm{V}$-shaped baffle/rib gives high efficiency to augment heat transfer rate and thermal performance. However, the installation of the V-shaped baffle/rib in the heating duct has a problem about the stability of the vortex generator. Therefore, we try to develop the vortex generator configuration with the two main aims: (1) maintain the thermal performance and heat transfer rate nearly as the $\mathrm{V}$-shaped baffles/rib and (2) increase the stability of the vortex generator when installed in the heat exchanger. The new design of the vortex generator is called "double V-ring (DVR)." The DVR is a combination between two types of the vortex generators: (1) V-shaped baffle/rib and (2) Orifice. The DVR may create the flow topology and heat transfer behaviors similarly as the $\mathrm{V}$-shaped baffle/rib. This means that the DVR may give nearly heat transfer rate and thermal performance nearly as $\mathrm{V}$-shaped baffle/rib but give a higher structure stabilization. Moreover, the discrete DVR is also created with the purpose to relieve the pressure loss when compared with the general configuration and to improve the air temperature distribution. The fluid flow and heat transfer features in the HED installed with the DVR are analyzed with the numerical technique. The variation of the thermal boundary layer on the duct walls or heat transfer surfaces is focused. The understandings of the flow feature and heat transfer configuration are an important knowledge for the thermal system development.

\section{Physical Configuration of the HED Inserted with the DVR}

The HED installed with three types of the DVR are plotted as Figure 1 . The hydraulic diameter $\left(D_{h}\right)$ of the square duct is equal to the duct height $(H), D_{h}=H=0.05 \mathrm{~m}$. Type I is the general configuration of the DVR, while types II and III are the discrete configuration of the DVR. For the present study, the laminar flow region with the Reynolds number of about 100-2000 is analyzed. The ring height at the middle of the HED is presented with " $a$," while the ring height on the upper-lower walls and sidewalls of the duct is presented with 

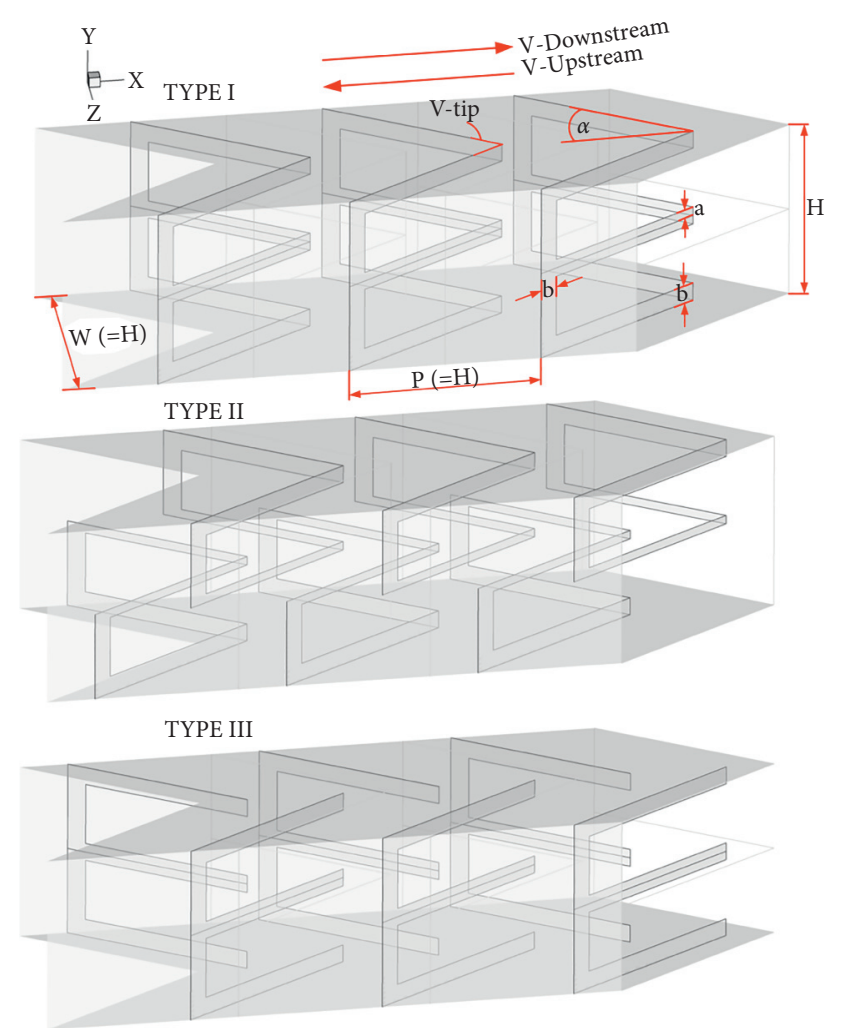

Figure 1: Computational domain of the HED installed with the different types of the DVR.

" $b$. ." The flow direction in the HED inserted with the DVR can be split into two directions. The V-apex of the DVR pointing upstream is named "V-Upstream," while the opposite setting is called "V-Downstream." The flow attack angle for all configurations of the DVR is about $30^{\circ}$, while the pitch spacing between the DVR $(P)$ is equal to the duct height $(P=H)$. The case studies of the HED fitted with the DVR are summarized in Table 1.

\section{Mathematical Foundation and Numerical Method}

The assumptions, boundary conditions, and initial conditions for the HED fitted with the DVR are concluded as follows:

(i) For the heat transfer mode, the forced convection in the HED is measured, while the natural convection and radiation heat transfer are disregarded.

(ii) The tested fluid is air with an initial temperature of $300 \mathrm{~K}$ (Prandtl number of 0.707 ). The air is assumed to be incompressible fluid due to low velocity.

(iii) The air properties are constant, because the variations of the fluid temperature in HED are not higher than $10^{\circ} \mathrm{C}\left(\Delta T \leq 10^{\circ} \mathrm{C}\right)$.

(iv) Body forced and viscous dissipation are disregarded. (v) No slip wall condition is utilized for all surfaces of the HED fitted with the DVR.

(vi) The flow and heat transfer structures in the HED fitted with the DVR are as steady conditions in three dimensions.

(vii) The air velocity is measured in terms of dimensionless variable, Reynolds number. The Reynolds number around 100-2000 (laminar regime at the entry condition) is considered for the present investigation.

(viii) The duct walls are set with constant temperature around $310 \mathrm{~K}$, while the DVR is assumed as an insulator.

(ix) Periodic condition [20] is applied for the entry-exit regimes of the computational model.

The computational domains of the HED installed with the DVR are answered by a commercial program (FLUENT). The significant equations for the numerical investigation of the HED that fitted the DVR are the continuity, the Navier-Stokes, and the energy equations, which are written as equations (1)-(3), respectively. In the numerical investigation, the continuity and momentum equations are discretized by power law scheme, while the energy equation is discretized with QUICK scheme. The numerical solutions are measured to be converged when the normalized residual values are less than $10^{-5}$ for all variables, but less than $10^{-9}$ only for the energy equation.

Continuity equation:

$$
\frac{\partial}{\partial x_{i}}\left(\rho u_{i}\right)=0 .
$$

Momentum equation:

$$
\frac{\partial\left(\rho u_{i} u_{j}\right)}{\partial x_{j}}=-\frac{\partial p}{\partial x_{i}}+\frac{\partial}{\partial x_{j}}\left[\mu\left(\frac{\partial u_{i}}{\partial x_{j}}+\frac{\partial u_{j}}{\partial x_{i}}\right)\right]
$$

Energy equation:

$$
\frac{\partial}{\partial x_{i}}\left(\rho u_{i} T\right)=\frac{\partial}{\partial x_{j}}\left(\Gamma \frac{\partial T}{\partial x_{j}}\right)
$$

where $\Gamma$ is the thermal diffusivity and is illustrated as

$$
\Gamma=\frac{\mu}{\operatorname{Pr}} \text {. }
$$

The air velocity in the HED fitted with the DVR is presented in terms of Reynolds number. The Reynolds number can be calculated as equation (5). The mean velocity, $\bar{u}$, is considered at the inlet condition of the HED:

$$
\operatorname{Re}=\frac{\rho \bar{u} D_{h}}{\mu} .
$$

The pressure loss across the HED fitted with the DVR is concluded with the dimensionless variable, friction factor. The friction factor is determined by

$$
f=\frac{(\Delta p / L) D_{h}}{1 / 2 \rho \bar{u}^{2}}
$$


TABLE 1: Case studies of the HED fitted with the DVR.

\begin{tabular}{lccccc}
\hline DVR type & Flow attack angle $(\alpha)$ & $a / H$ & $b / H$ & Flow direction & Reynolds number \\
\hline Type I & $30^{\circ}$ & $0.025,0.05,0.075,0.1$ & $0.05,0.10,0.15,0.20$ & $\begin{array}{c}\text { V-upstream } \\
\text { V-downstream }\end{array}$ & $100-2000$ \\
\hline Type II & $30^{\circ}$ & $0.025,0.05,0.075,0.1$ & $0.05,0.10,0.15,0.20$ & $\begin{array}{c}\text { V-upstream } \\
\text { V-downstream }\end{array}$ & $100-2000$ \\
\hline Type III & $30^{\circ}$ & $0.025,0.05,0.075,0.1$ & $0.05,0.10,0.15,0.20$ & $\begin{array}{c}\text { V-upstream } \\
\text { V-downstream }\end{array}$ & $100-2000$ \\
\hline
\end{tabular}

The heat transfer rate in the HED installed with the DVR is presented by local Nusselt number and average Nusselt number as equations (7) and (8), respectively,

$$
\begin{aligned}
\mathrm{Nu}_{x} & =\frac{h_{x} D_{h}}{k}, \\
\mathrm{Nu} & =\frac{1}{A} \int \mathrm{Nu}_{x} \partial A .
\end{aligned}
$$

The thermal enhancement factor (at similar pumping power) of the HED fitted with the DVR is calculated as equation (9). The thermal enhancement factor is defined as the ratio between the heat transfer coefficient of the HED fitted with the DVR, $h$, and the heat transfer coefficient of the smooth duct, $h_{0}$ :

$$
\mathrm{TEF}=\left.\frac{h}{h_{0}}\right|_{\mathrm{pp}}=\left.\frac{\mathrm{Nu}}{\mathrm{Nu}_{0}}\right|_{\mathrm{pp}}=\frac{\left(\mathrm{Nu} / \mathrm{Nu}_{0}\right)}{\left(f / f_{0}\right)^{1 / 3}} .
$$

\section{Numerical Validation}

An important step for the numerical investigation is numerical validation. The numerical validation can help guarantee the reliance and accuracy of the numerical solution. The numerical validation of the present investigation can be divided into two topics: (1) smooth square channel validation and (2) grid independence. The comparisons of the Nusselt number and friction factor between the present results with the values from the correlations [21] are done for the smooth duct validation. As the comparison, the numerical results show that both Nusselt number and friction factor are in similar trend for all Reynolds numbers. In addition, the deviated values of the Nusselt number and friction factor are around $\pm 0.8 \%$ and $\pm 2 \%$, respectively.

For the grid independence test, the comparison for different grid cells of the HED installed with the DVR ( $a$ ) $H=0.05, b / H=0.15$, type $\mathrm{I}, \mathrm{V}$-Downstream) is done. The optimum grid cell can help save computer resource and investigation time. The grid cells around 120000, 180000, 240000, and 360000 of the HED fitted with the DVR are compared. The growth of the grid cell from 180000 to 240000 has no effect for both Nusselt number and friction factor values. Thus, the grid number around 180000 cells is selected for all studied cases of the HED fitted with the DVR.

\section{Numerical Result}

The numerical results of the HED fitted with the DVR can be separated into four parts: (1) influences of $b / H$, (2) influences of $a / H,(3)$ influences of flow direction, and (4) performance analysis for all DVR types. The flow mechanisms and heat transfer characteristics in the HED inserted with the DVR at various $a / H$ and $b / H$ values are illustrated. The thermal performance, Nusselt number ratio, and friction factor ratio for the HED fitted with three types of the DVR are shown.

5.1. Influences of $b / H$. Figures $2-4$ show the longitudinal vortex streams in the HED installed with various $b / H$ values of types I, II, and III DVR, respectively. As the figures, the longitudinal vortex flows are detected in all cases, especially, at $b / H>0.10$. The longitudinal vortex streams are an important phenomenon, which helps improve the heat transfer potentiality in the HED. The longitudinal vortex flows annoy thermal boundary layer on the duct walls. The thermal boundary layer disturbance is the main reason for the heat transfer augmentation. Moreover, the longitudinal vortex streams also improve better fluid blending, which is another cause for the heat transfer increment. The flow structures in the tested section with various $b / H$ are in near pattern. When augmenting the $b / H$ value, the vortex strength is enhanced, while the longitudinal vortex pitch decreases. The vortex strength directly affects the disturbed thermal boundary layer and the increased heat transfer rate. For all types, $b / H=0.20$ brings the highest heat transfer rate, while $b / H=0.05$ gives the opposite result.

Figure 5 plots the diffusion of the fluid temperature in the HED fitted with various DVR types and $b / H$ values. The temperature contours are a guide to check the variation of the thermal boundary layer. As the figure, the change of the thermal boundary layer in the HED is obviously found for all investigated cases. The DVR in the HED forms the longitudinal vortex streams, which impinge on various positions of the duct walls. The impingement of the vortex streams is a significant behavior for the development of the heat transfer rate due to the decrease of the thermal boundary layer thickness. The thermal boundary layer thickness decreases when augmenting $b / H$ value, especially, at the left-right zones of the planes. Because $b / H=0.20$ gives the highest vortex power, therefore, the thermal boundary layer disruption is definitely seen in this case, while $b / H=0.05$ performs the opposite yield.

Figure 6 presents the Nusselt number contours on the duct walls of the HED fitted with various DVR types and $b / H$ values. For types I and III, $b / H=0.05$ provides high Nusselt number (orange contours) at the upper-lower regimes of the HED. The heat transfer potentiality at the upper-lower walls of the HED decreases when $0.05 \leq b / H \leq 0.1$ but is enhanced 


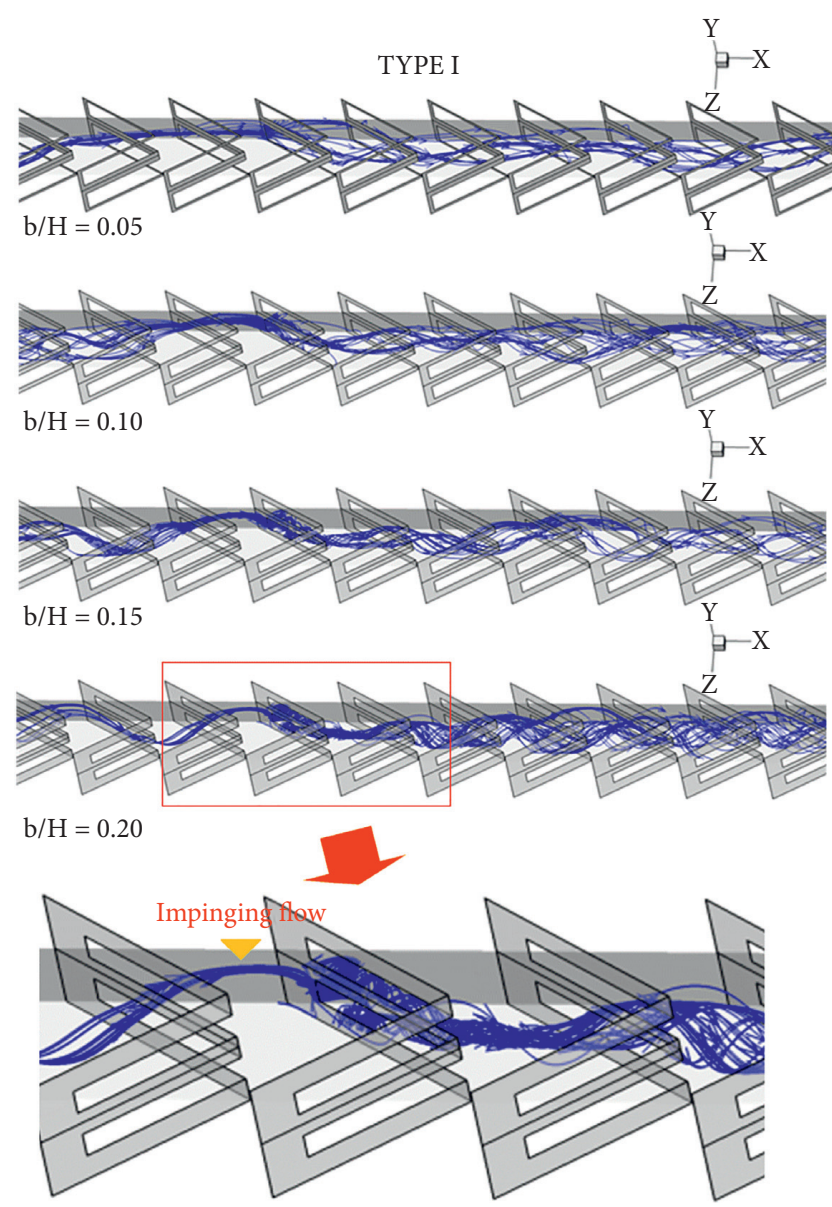

FIGURE 2: Longitudinal vortex streams of the HED fitted with the DVR (type I) for various $b / H$ at $a / H=0.10, V$-downstream, and $\operatorname{Re}=600$.

when $b / H>0.1$. The Nusselt number at the left-right sidewalls is enhanced when augmenting $b / H$ value.

For type II, $b / H=0.05$ lets the lowest heat transfer potentiality, while $b / H=0.20$ offers the reversed result. It is obviously detected that the Nusselt number extends when growing $\mathrm{b} / \mathrm{H}$ value for all sidewalls. The variations of peaks are due to the variations of the impinging flows when varying DVR types and parameters.

5.2. Influences of $a / H$. Figures $7-9$ plot the longitudinal vortex streams in the HED installed with the DVR at various $a / H$ values for types I, II, and III, respectively, at similar $b / H$. As the figures, the longitudinal vortex streams are clearly seen in all studied examples. The flow topologies are found to be in a near pattern, because the main flow structure depends on the DVR at the upper-lower walls (or depends on the $b / H$ values). Over the studied rang, the $a / H$ slightly affects the growth or reduction of the vortex strength. The longitudinal vortex pitch slightly changes when changing a/ $H$.

The temperature contours in transverse planes of the HED installed with various DVR types and $a / H$ values are plotted in Figure 10. For types I and III, the fluid mixing is

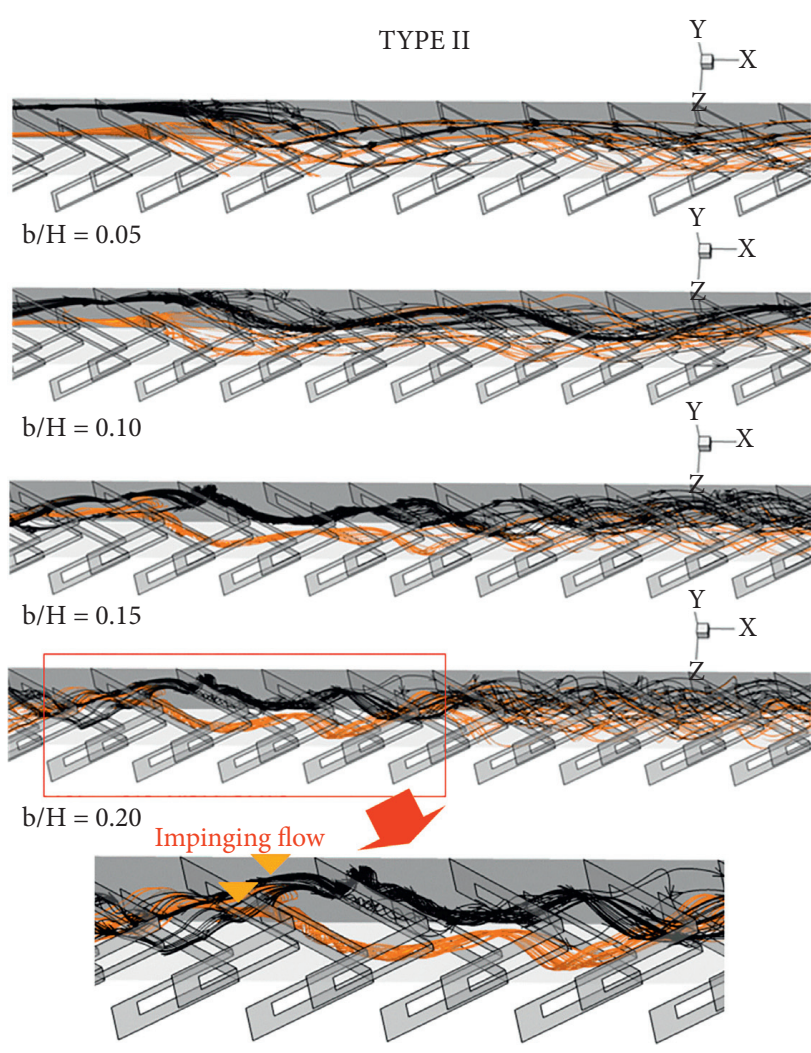

FIgURE 3: Longitudinal vortex streams of the HED fitted with the DVR (type II) for various $b / H$ at $a / H=0.10, \mathrm{~V}$-downstream and $\operatorname{Re}=600$.

quite poor when augmenting $a / H$. The heat transfer structures of types I and III are found to be in near profile. The heat transfer rate slightly decreases when increasing $a / H$ (see Figure 11).

For type II, the fluid temperature contours in all $a / H$ values are found to be in near pattern. The heat transfer rate rises when augmenting $a / H$ (see Figure 11).

5.3. Influences of the Flow Direction. The streamlines in transverse planes in the HED fitted with various DVR types and flow directions are plotted in Figure 12. As the figure, the DVR creates four main vortex flows for both flow directions. The vortex streams near the upper-lower walls are created by the part of the DVR on the upper-lower walls, while the vortex flows at the middle of the HED are produced by the part of the DVR at the middle of the HED (see Figure 13). The vortex rotation is not in a similar direction when changing flow direction. This topology affects the change of the heat transfer behavior in the HED. Moreover, the impingement of the vortex streams may change when varying flow direction. The position of the vortex core in transverse positions depends on the DVR types and parameters. Due to the symmetric structure of the DVR, the symmetry flows at the upper-lower and left-right parts are detected for type I, while the symmetry streams at the left-right regimes and upper-lower regions are observed for types II and III, respectively. 


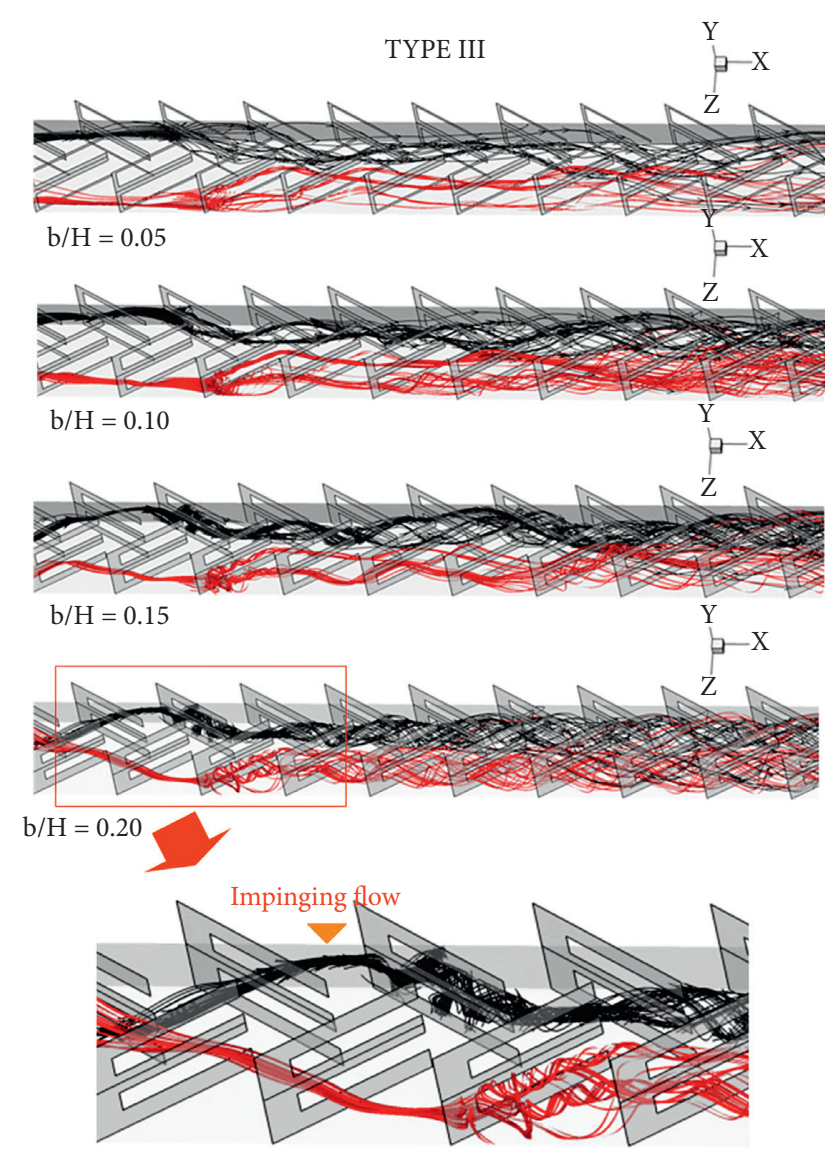

FIGURE 4: Longitudinal vortex streams of the HED fitted with the DVR (type III) for various $b / H$ at $a / H=0.10, \mathrm{~V}$-downstream, and $\mathrm{Re}=600$.

Figure 14 shows the fluid temperature spreading in transverse planes of the HED installed with various DVR types and flow directions. As seen, better air blending and thermal boundary layer disturbance near the HED walls are found for both flow directions. The disturbed thermal boundary layer is apparently found at the left-right zones for the V-Downstream direction, while it is seen at the upperlower regimes for the $\mathrm{V}$-Upstream direction. This means that the $\mathrm{V}$-Downstream lets the vortex streams, which impacts the left-right parts of the HED, while the V-Upstream performs the vortex streams, which bounces the upper-lower regimes of the HED. The change of the thermal boundary layer is related to the peak of the heat transfer regime (Nusselt number contours) as seen in Figure 15. The disturbed thermal boundary layer significantly affects the augmentation of the Nusselt number on the duct walls.

5.4. Performance Analysis. The relations of the Nusselt number ratio $\left(\mathrm{Nu} / \mathrm{Nu}_{0}\right)$, friction factor ratio $\left(f / f_{0}\right)$, and thermal enhancement factor (TEF) with the Reynolds number at various $a / H, b / H$, and flow directions are presented in this part.

5.4.1. Type I. Figures 16(a)-16(d) report the relations of the $\mathrm{Nu} / \mathrm{Nu}_{0}$ with the Reynold number at various $b / H$ and flow directions of type I for $a / H=0.025,0.05,0.075$, and 0.1 , respectively. Normally, the $\mathrm{Nu} / \mathrm{Nu}_{0}$ extends with augmenting Reynolds number for all investigated examples. The heat transfer potentiality in the HED grows when increasing $b / H$ magnitude, except for $0.15 \leq b / H \leq 0.20$ of $a / H=0.025$ and 0.05 , in which the $\mathrm{Nu} / \mathrm{Nu}_{0}$ values are very close for all Reynolds numbers. The $\mathrm{Nu} / \mathrm{Nu}_{0}$ in the HED inserted with the DVR is around 1.22-14.32, 1.40-14.18, 1.43-12.19, and 1.74-12.81, respectively, for $a / H=0.025,0.05,0.075$, and 0.1 of the V-Downstream arrangement, while it is around $1.07-12.82,1.22-14.45,1.43-12.19$, and 1.74-12.81, respectively, for the $\mathrm{V}$-Upstream arrangement.

Figures $17(\mathrm{a})-17(\mathrm{~d})$ plot the relation of the $f / f_{0}$ with the Reynolds number at different $b / H$ and flow directions for $a /$ $H=0.025,0.05,0.075$, and 0.1 , respectively, in the HED inserted with the type I DVR. The $f / f_{0}$ tends to increase when augmenting $\mathrm{b} / H, a / H$, and Reynolds number. In almost all cases, the V-Upstream direction performs higher friction loss than the V-Downstream direction. For the V-Downstream direction, the $f / f_{0}$ is found to be about 1.76-75.81, 2.12-83.58, 2.52-99.70, and 3.00-129.25, respectively, for $a /$ $H=0.025,0.05,0.075$, and 0.1 . For the V-Upstream direction, the $f / f_{0}$ is around 1.77-78.98, 2.14-98.97, 2.56-119.19, and 3.09-150.00, respectively, for $a / H=0.025,0.05,0.075$, and 0.1 .

Figures $18(a)-18(d)$ report the relativity of the TEF with the Reynolds number with various $b / H$ and flow direction for $a / H=0.025,0.05,0.075$, and 0.1 , respectively, in the HED inserted with the type I DVR. As the figures, the TEF augments when growing Reynolds number for all examined cases. The greatest TEF is found at $b / H=0.15,0.15,0.20$, and 0.05 around $3.64,3.69,2.63$, and 2.88 , respectively, for al $H=0.025,0.05,0.075$, and 0.1 of the V-Downstream pointing at $\mathrm{Re}=2000$. For the $\mathrm{V}$-Upstream pointing, the greatest TEF is detected at $b / H=0.10,0.10,0.15$, and 0.15 around $4.17,3.81,3.57$, and 3.25, respectively, of $a / H=0.025$, $0.05,0.075$, and 0.1 at $\operatorname{Re}=2000$.

5.4.2. Type II. The $\mathrm{Nu} / \mathrm{Nu}_{0}$ versus Reynolds number in the HED installed with the type II DVR is plotted in Figures $19(\mathrm{a})-19(\mathrm{~d})$, respectively, for $a / H=0.025,0.05$, 0.075 , and 0.1 . For the $\mathrm{V}$-Downstream arrangement, the $\mathrm{Nu} /$ $\mathrm{Nu}_{0}$ is around 1.24-13.99, 1.35-14.61, 1.46-15.02, and $1.57-15.86$ for $a / H=0.025,0.05,0.075$, and 0.1 . For the $\mathrm{V}$-Upstream arrangement, the potentiality of heat transfer in the HED is higher than the smooth duct around 1.05-10.62, $1.16-13.90,1.25-14.94$, and 1.24-12.96 times, for a/ $H=0.025,0.05,0.075$, and 0.1 , respectively.

The $f / f_{0}$ versus Re in the HED inserted with the type II DVR is presented as Figures 20(a)-20(d), respectively, for al $H=0.025,0.05,0.075$, and 0.1 . The $f / f_{0}$ is around $1.85-62.63$, 2.15-73.92, 2.43-87.67, and 2.77-109.68, respectively, for al $H=0.025,0.05,0.075$, and 0.1 when considered at the $\mathrm{V}$-Downstream arrangement. For the V-Upstream arrangement, the friction loss is upper than the smooth duct around 1.86-55.09, 2.17-64.62, 2.47-75.54, and 2.82-89.61 times, respectively, for $a / H=0.025,0.05,0.075$, and 0.1 .

Figures 21(a)-21(d) offer the relations of the TEF with the Reynolds number at different $\mathrm{b} / \mathrm{H}$ and flow directions for 


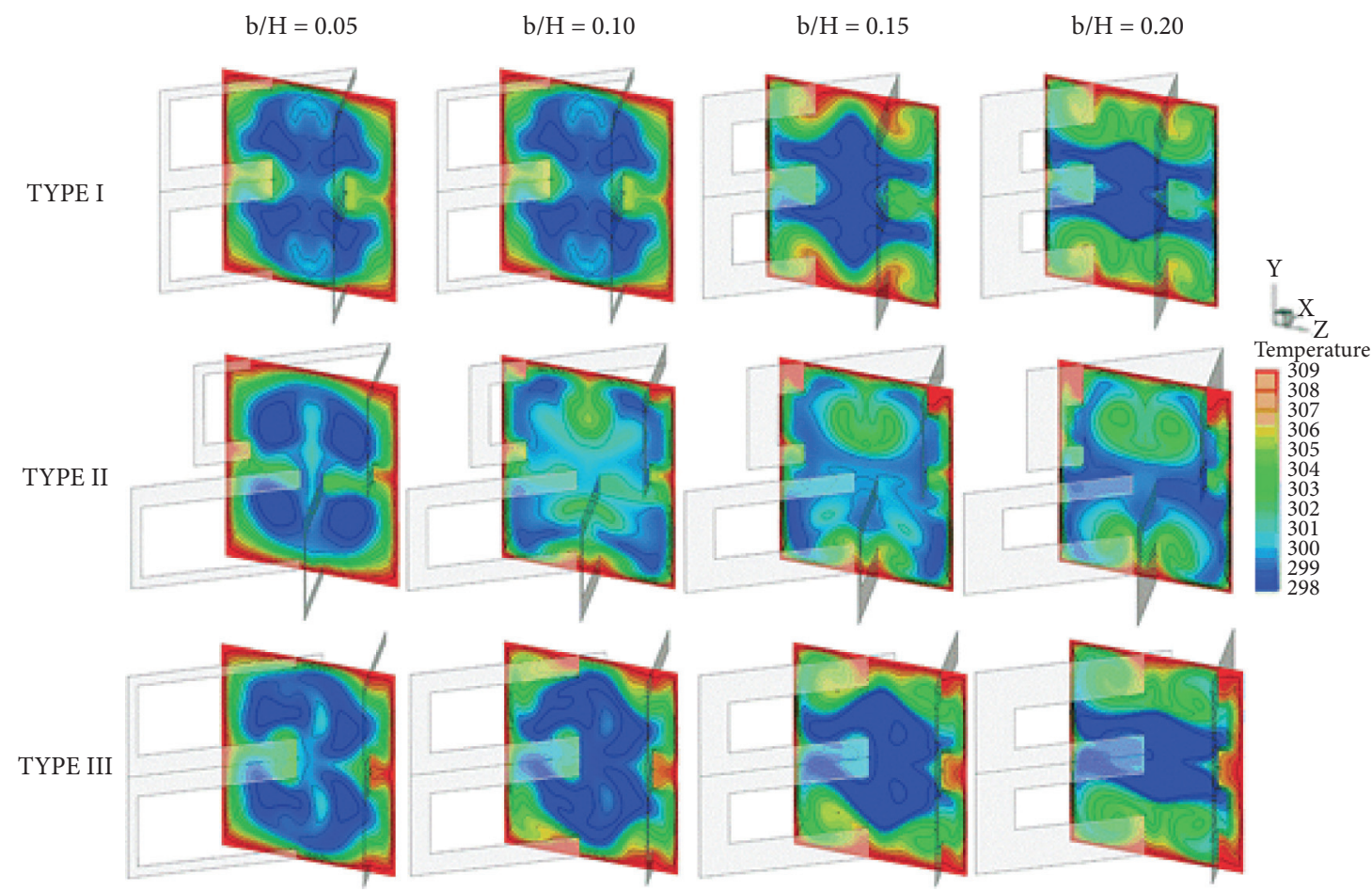

FIGURE 5: Temperature distributions in $y$ - $z$ plane of the HED fitted with various DVR types and $b / H$ at $a / H=0.10$, V-downstream, and $\operatorname{Re}=600$.
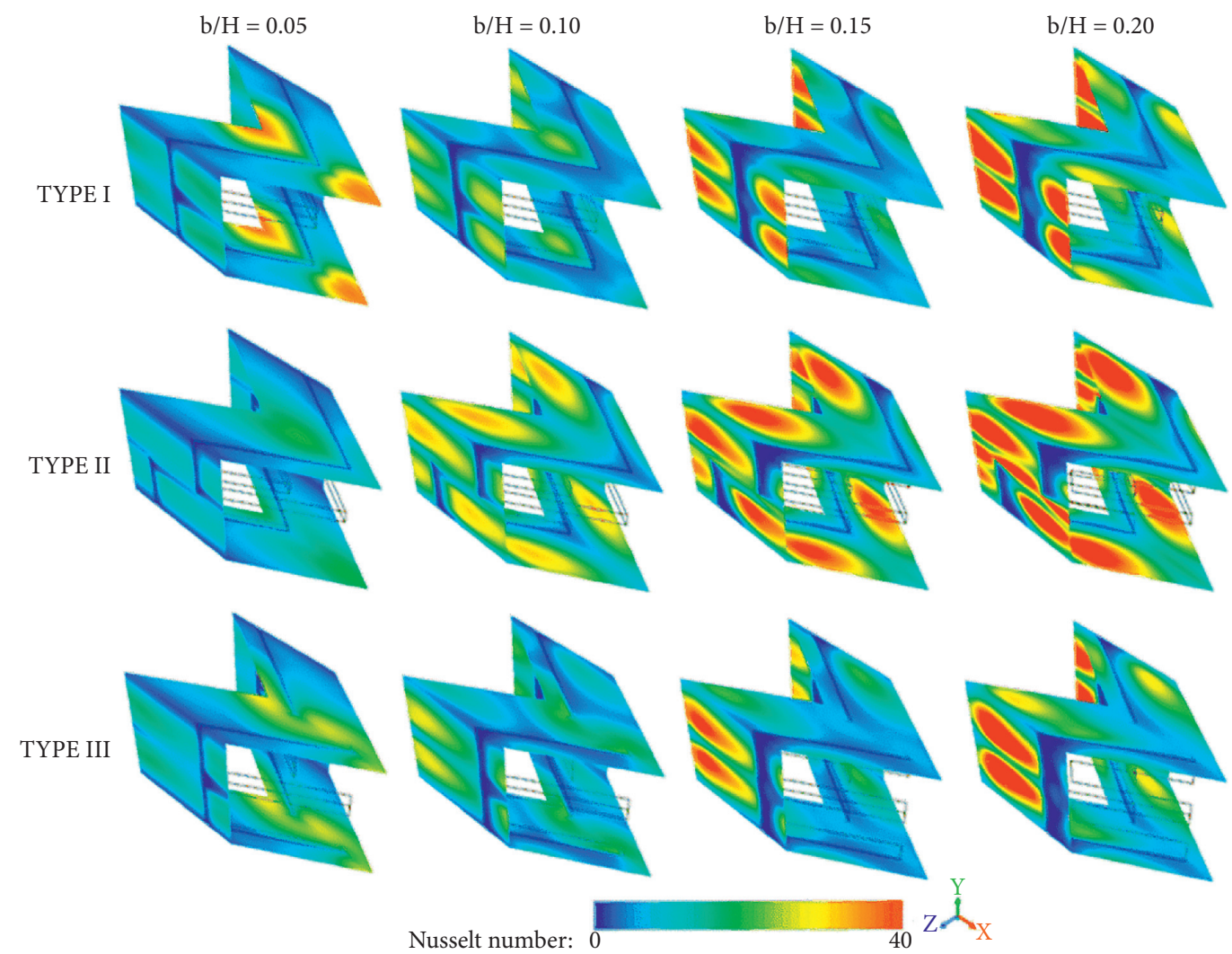

Nusselt number: 0

FIGURE 6: Local Nusselt number distributions of the HED fitted with various DVR types and $b / H$ at $a / H=0.10, \mathrm{~V}$-downstream, and Re $=600$. 


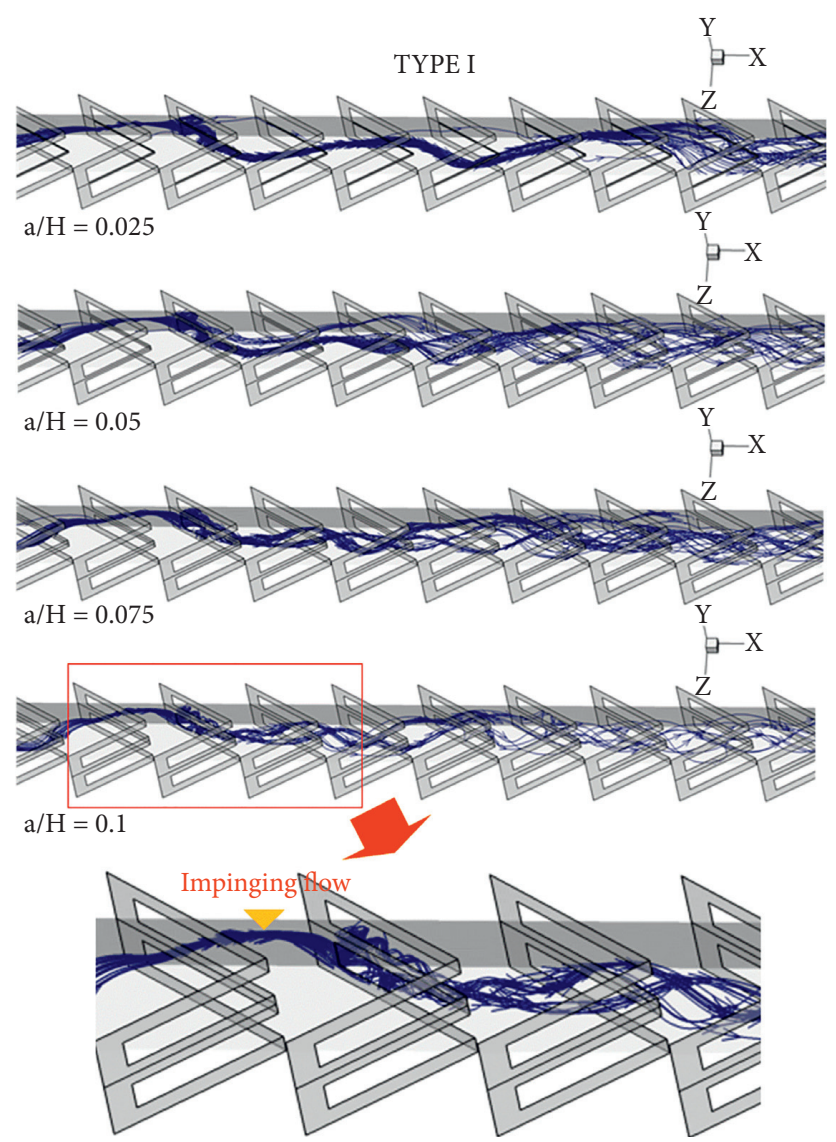

FIGURE 7: Longitudinal vortex streams of the HED fitted with the DVR (type I) for various $a / H$ at $b / H=0.15, \mathrm{~V}$-downstream, and Re $=800$.

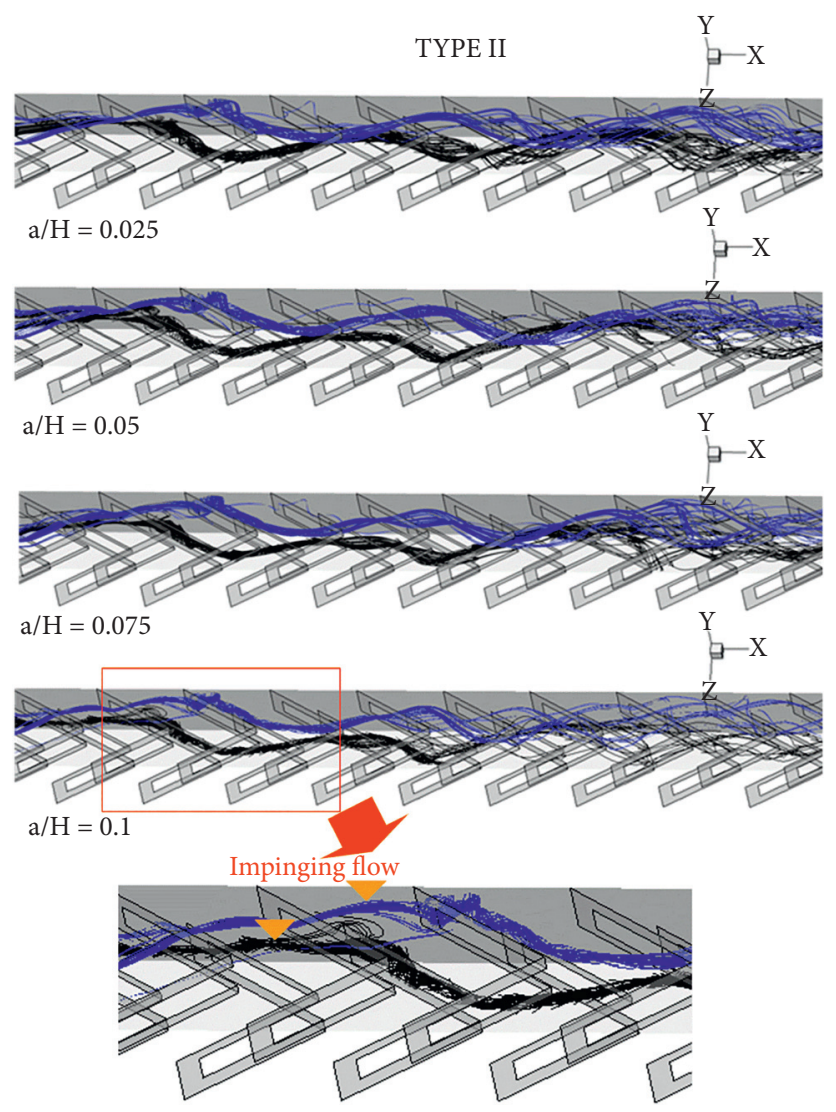

FIgURE 8: Longitudinal vortex streams of the HED fitted with the DVR (type II) for various $a / H$ at $b / H=0.15, \mathrm{~V}$-downstream, and Re $=800$. 


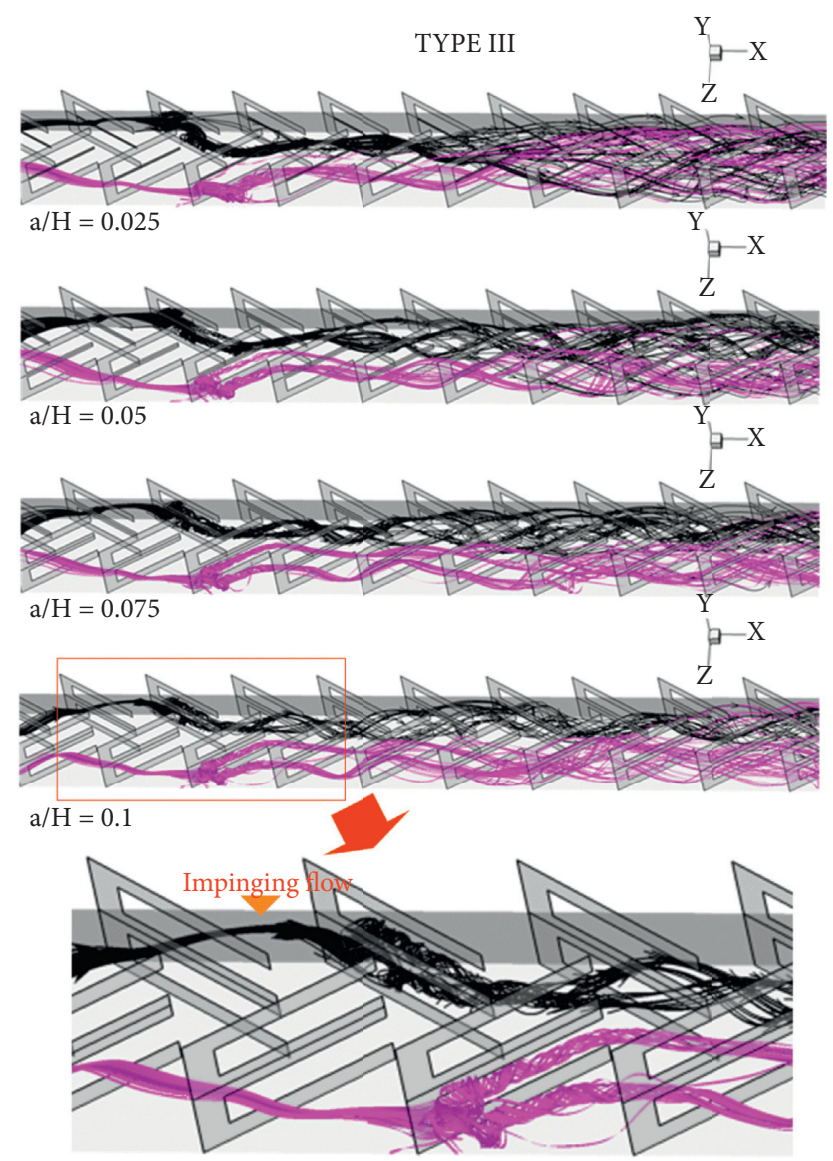

FIGURE 9: Longitudinal vortex stream of the HED fitted with the DVR (type III) for various $a / H$ at $b / H=0.15, \mathrm{~V}$-downstream, and Re $=800$.

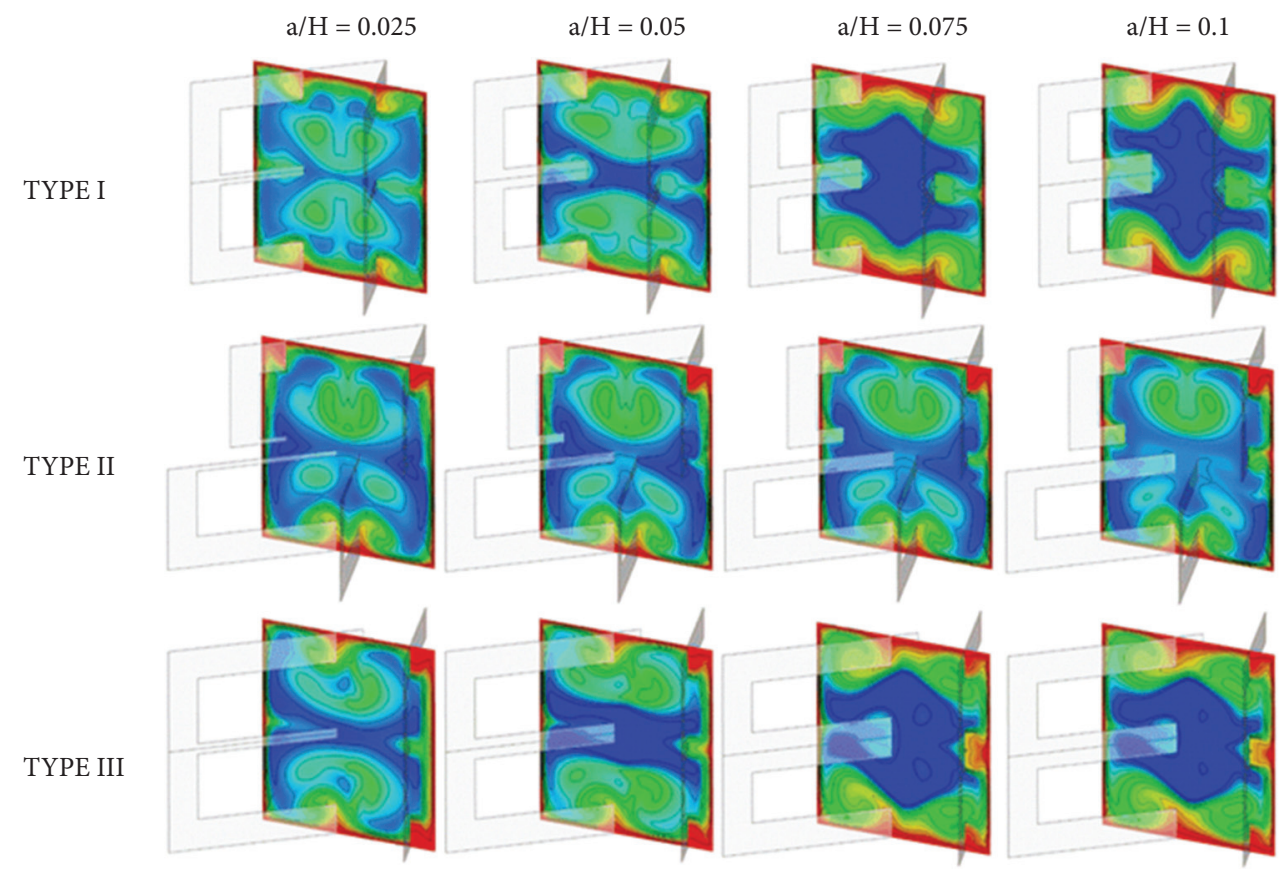

Figure 10: Temperature distributions in $y$ - $z$ plane of the HED fitted with various DVR types and $a / H$ at $b / H=0.15$, V-downstream, and $\mathrm{Re}=800$. 


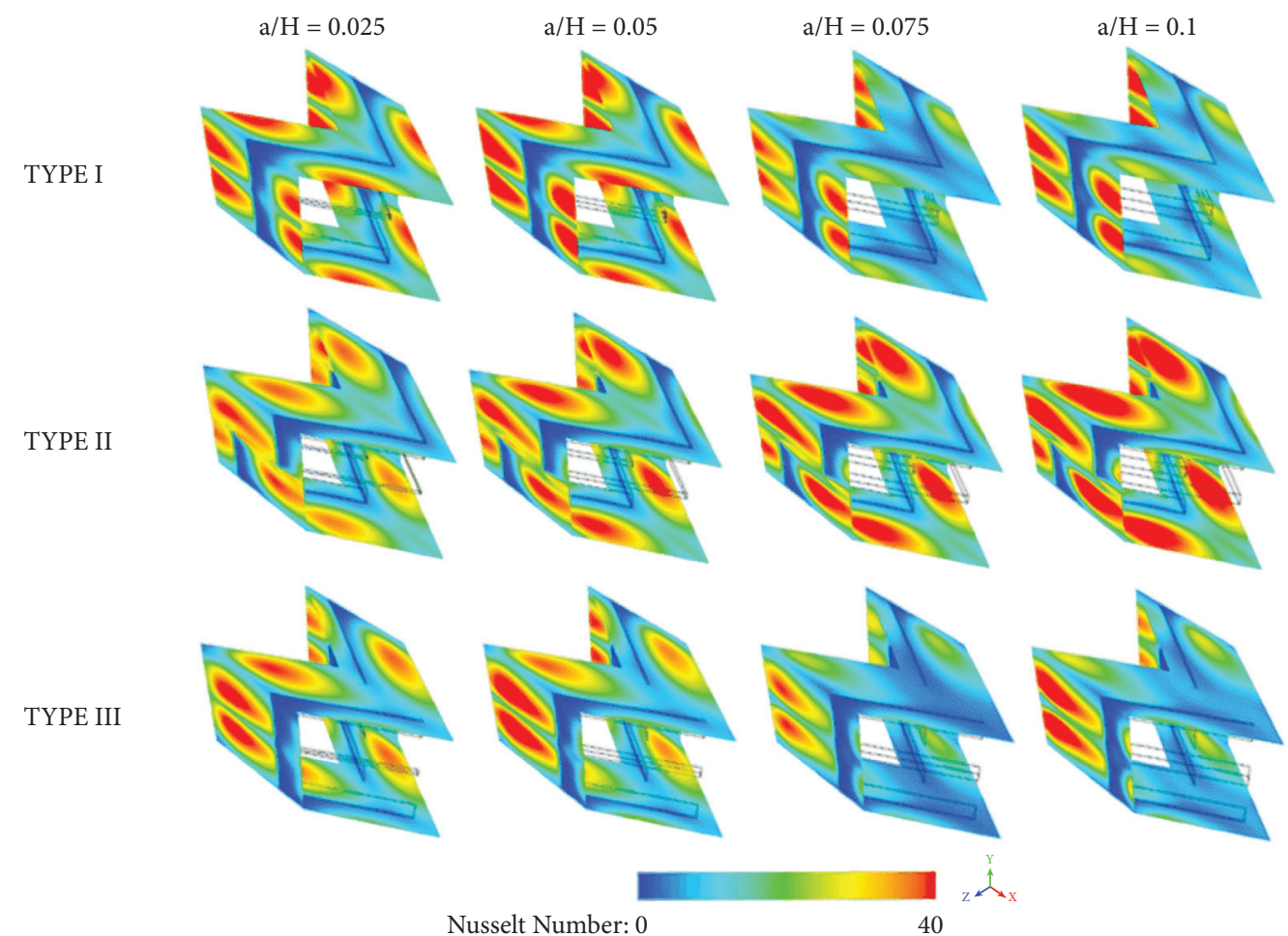

FIgURE 11: Local Nusselt number distributions of the HED fitted with various DVR types and $a / H$ at $b / H=0.15, \mathrm{~V}$-downstream, and $\mathrm{Re}=800$.
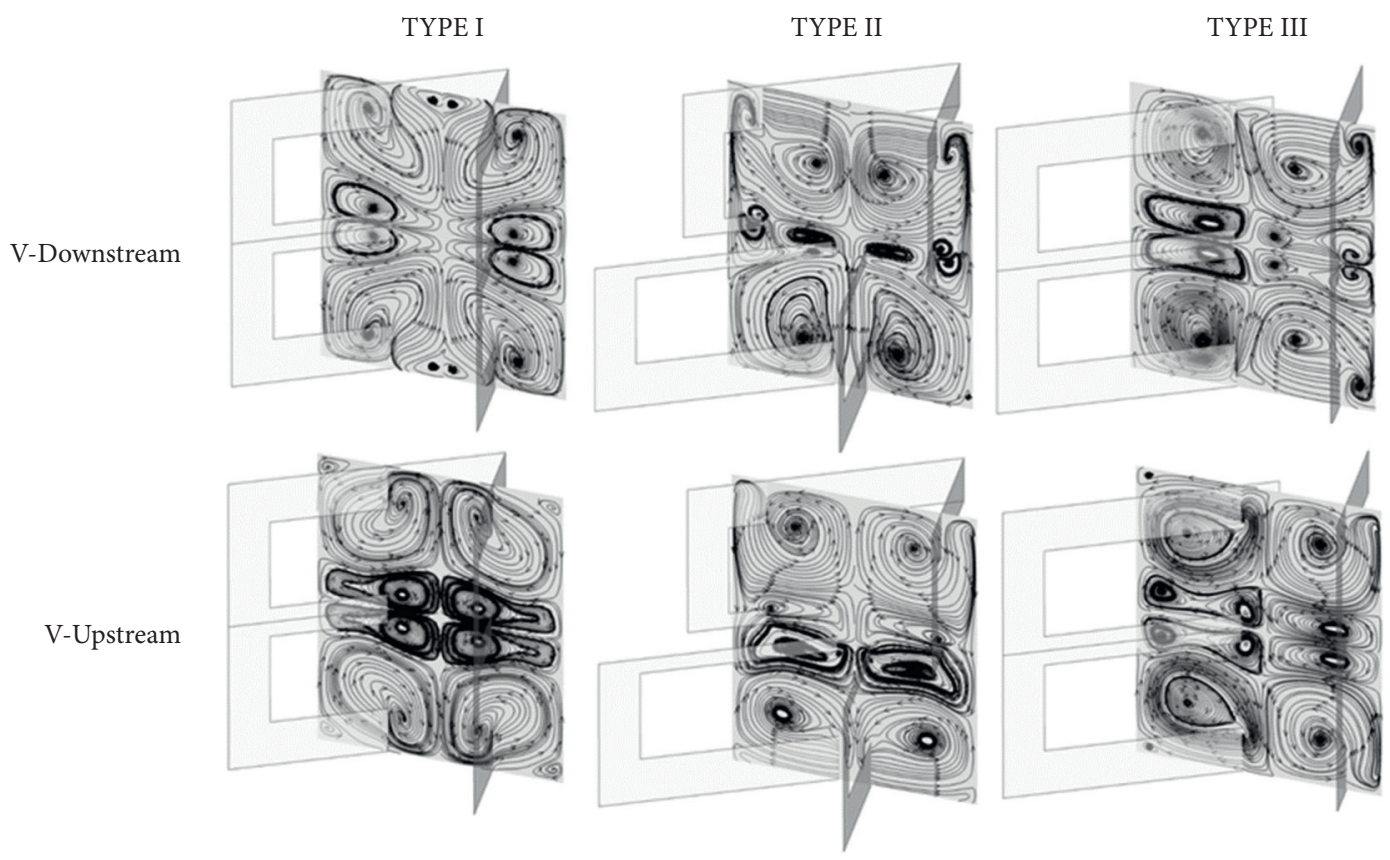

FIGURE 12: Streamlines in $y$ - $z$ plane of the HED fitted with various DVR types and flow directions at $a / H=0.05, b / H=0.15$, and $\operatorname{Re}=1000$.

$a / H=0.025,0.05,0.075$, and 0.1 , respectively, of the type II DVR. The optimum TEF is found at $b / H=0.15,0.15,0.10$, and 0.10 around $3.81,3.71,3.77$, and 3.84, respectively, for $a /$ $H=0.025,0.05,0.075$, and 0.1 of the V-Downstream arrangement at $\mathrm{Re}=2000$. The maximum $\mathrm{TEF}$ of the $\mathrm{V}$-Upstream arrangement is detected at $b / H=0.10,0.15$, 0.10 , and 0.10 around $4.13,4.13,3.94$, and 3.97 , respectively, for $a / H=0.025,0.05,0.075$, and 0.1 . 


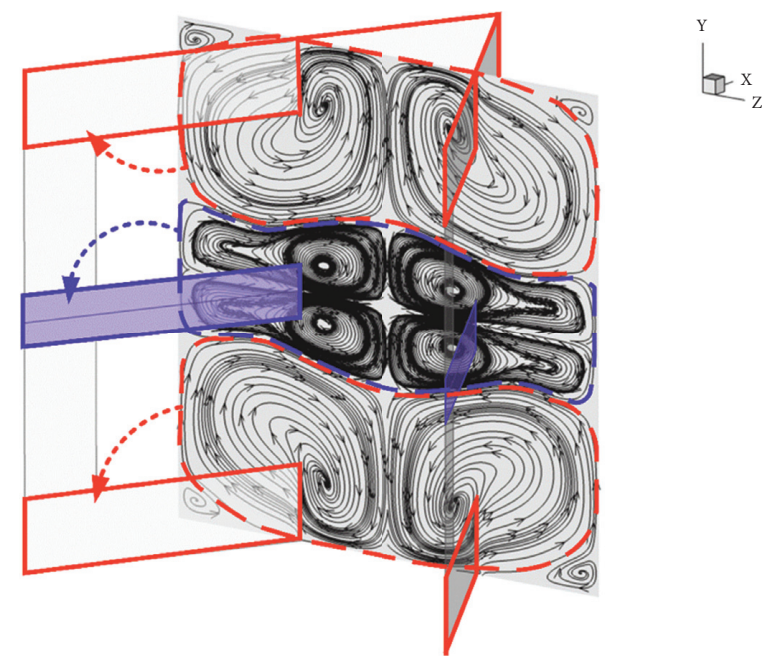

Figure 13: Flow description in the HED fitted with the DVR.

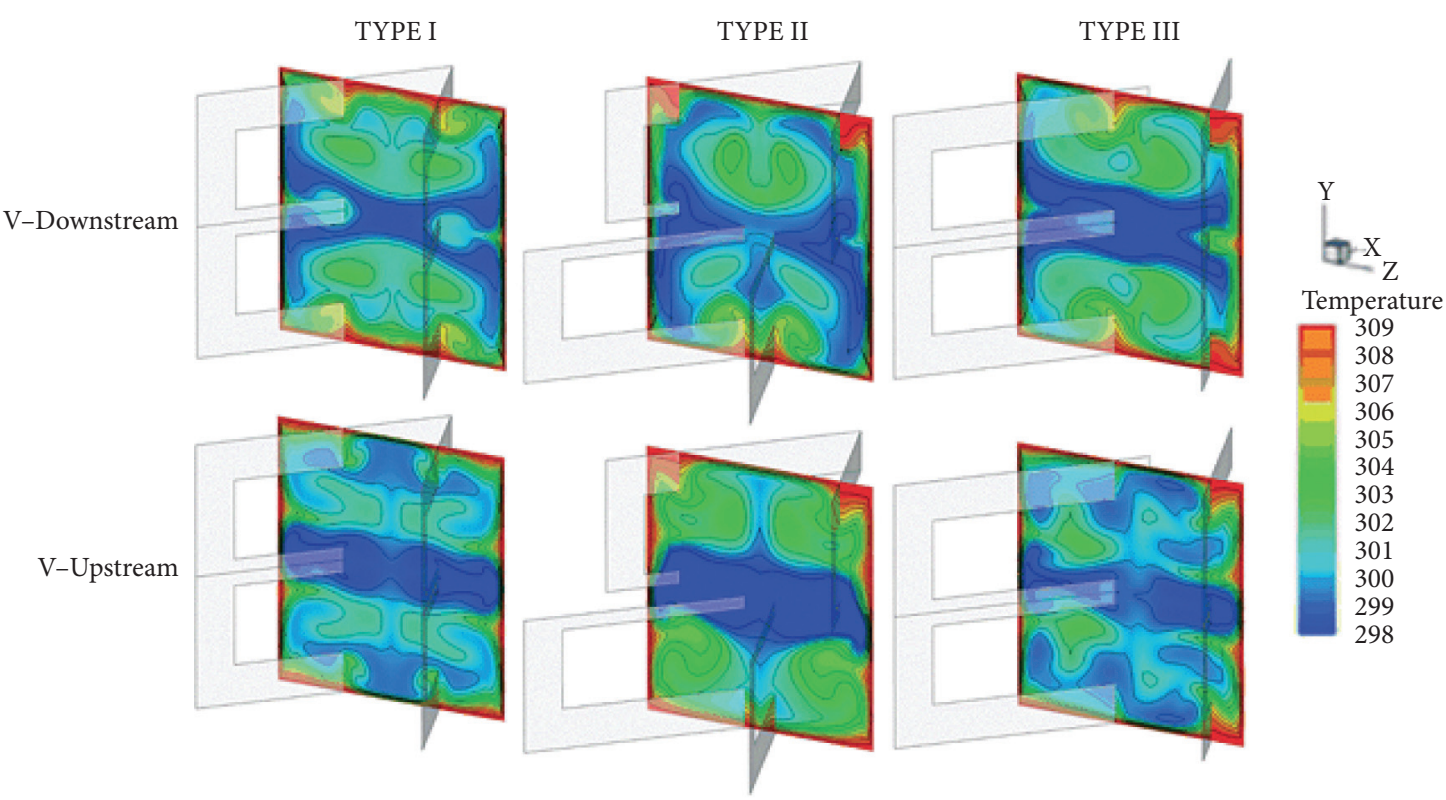

FIGURE 14: Temperature distributions in $y$ - $z$ plane of the HED fitted with various DVR types and flow directions at $a / H=0.05, b / H=0.15$, and $\mathrm{Re}=1000$.

5.4.3. Type III. The variations of the $\mathrm{Nu} / \mathrm{Nu}_{0}$ with the Reynolds number at different $\mathrm{b} / \mathrm{H}$ and flow directions in the HED fitted with the type III DVR of $a / H=0.025,0.05,0.075$, and 0.1 are depicted as Figures $22(\mathrm{a})-22(\mathrm{~d})$, respectively. The heat transfer potentiality of the HED installed with the type III DVR of the V-Downstream direction is greater than the plain duct around 1.18-11.98, 1.37-11.74, 1.54-12.06, and $1.71-11.8$, respectively, for $a / H=0.025,0.05,0.075$, and 0.1 . For the V-Upstream arrangement, the $\mathrm{Nu} / \mathrm{Nu}_{0}$ is around $1.08-11.46,1.22-12.88,1.43-14.20$, and 1.66-13.44 for al $H=0.025,0.05,0.075$, and 0.1 , respectively.

Figures 23(a)-23(d) plot the variations of the $f / f_{0}$ with the Reynold number at different $b / H$ and flow directions in the HED inserted with the type III DVR for $a / H=0.025,0.05$, 0.075 , and 0.1 , respectively. The friction loss in the HED inserted with the V-Downstream of the type III DVR is found to be around 1.74-55.65, 2.05-64.82, 2.43-76.89, and 2.85-90.50 times upper than the smooth duct, respectively, for $a / H=0.025,0.05,0.075$, and 0.1 . For the V-Upstream arrangement, the DVR with $a / H=0.025,0.05,0.075$, and 0.1 performs the friction loss upper than the smooth duct around 1.77-65.76, 2.14-76.36, 2.55-89.61, and 3.05-107.04 times, respectively.

The TEF versus the Reynolds number for the HED inserted with the type III DVR are plotted in Figures 24(a)24 (d) for $a / H=0.025,0.05,0.075$, and 0.1 , respectively. The maximum TEF is found at $b / H=0.10,0.15,0.20$, and 0.05 around $3.71,3.51,2.84$, and 2.83, respectively, for al $H=0.025,0.05,0.075$, and 0.1 at $\operatorname{Re}=2000$ of the $\mathrm{V}$-Downstream pointing. For the V-Upstream pointing at 


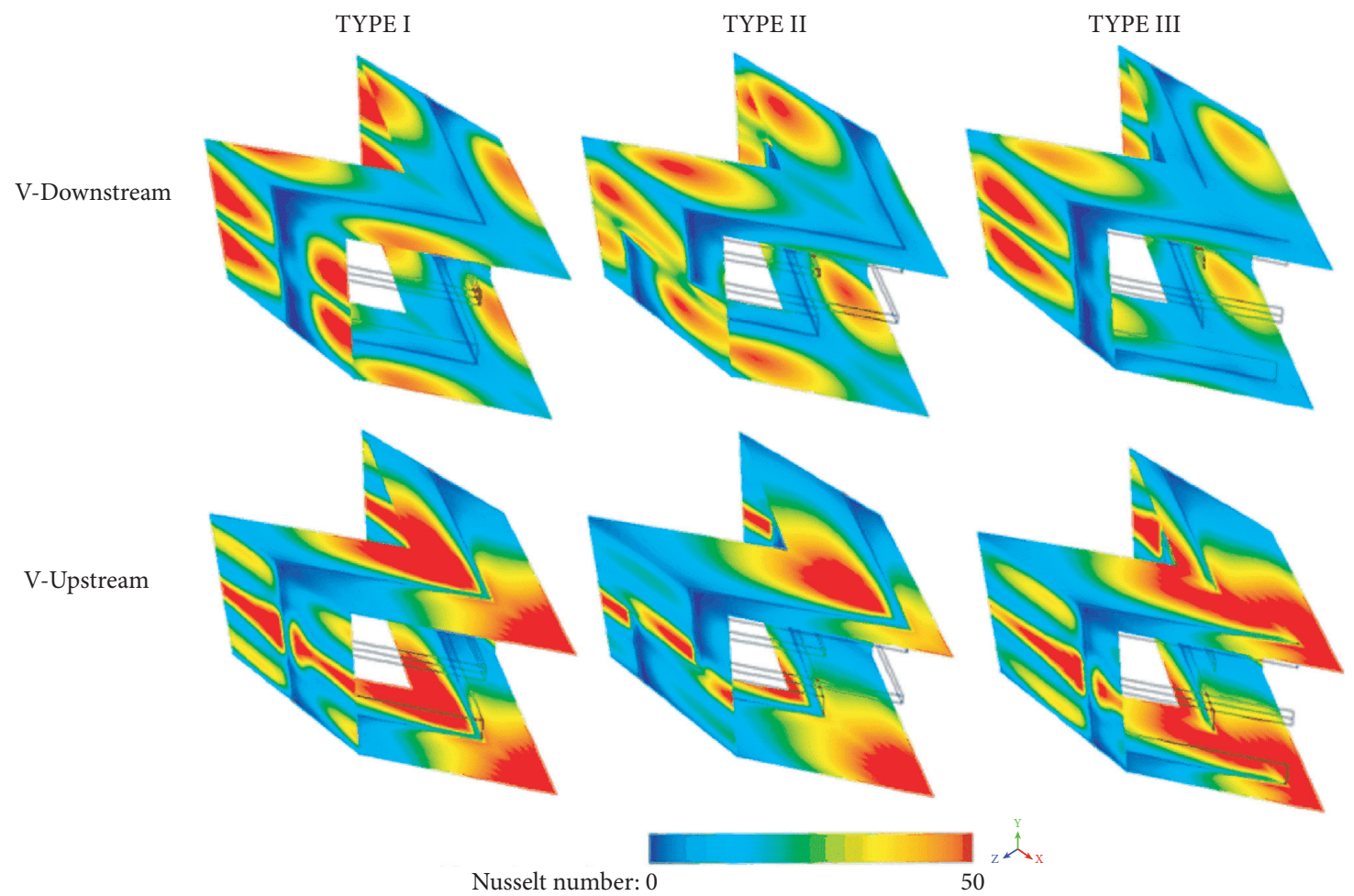

FIgURE 15: Local Nusselt number distribution of the HED fitted with various DVR types and flow at $a / H=0.05, b / H=0.15$, and Re $=1000$.

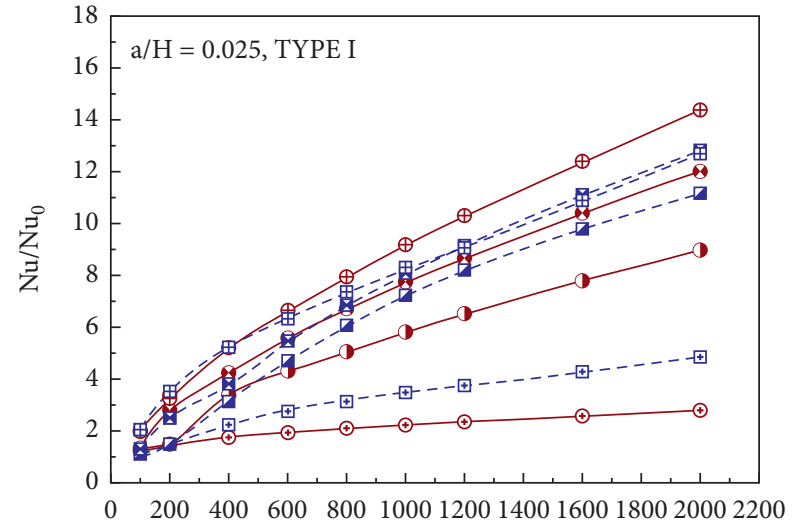

$\operatorname{Re}$

\begin{tabular}{|c|c|}
\hline V-Downstream : & V-Upstream : \\
\hline$-\odot-\mathrm{b} / \mathrm{H}=0.05$ & - 田- b/H $=0.05$ \\
\hline$-\mathrm{b} / \mathrm{H}=0.10$ & $-\square-\mathrm{b} / \mathrm{H}=0.10$ \\
\hline$-\mathrm{b} / \mathrm{H}=0.15$ & $-\mathbf{\mathbf { v }}-\mathrm{b} / \mathrm{H}=0.15$ \\
\hline$-\mathrm{b} / \mathrm{H}=0.20$ & $-\boxplus-\mathrm{b} / \mathrm{H}=0.20$ \\
\hline
\end{tabular}

(a)

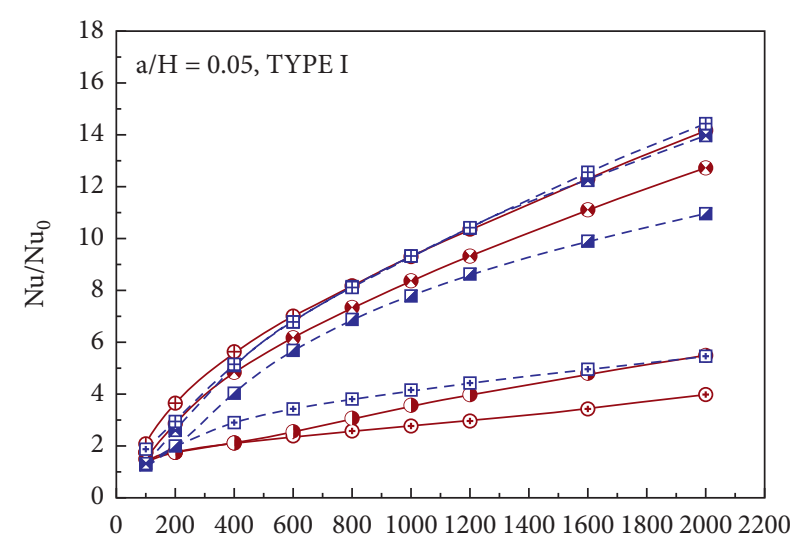

Re

$\begin{array}{ll}\text { V-Downstream : } & \text { V-Upstream : } \\ -\odot-\mathrm{b} / \mathrm{H}=0.05 & - \text {-田 } \mathrm{b} / \mathrm{H}=0.05 \\ -\mathrm{B}-\mathrm{b} / \mathrm{H}=0.10 & -\square-\mathrm{b} / \mathrm{H}=0.10 \\ \rightarrow-\mathrm{b} / \mathrm{H}=0.15 & -\mathbf{-}-\mathrm{b} / \mathrm{H}=0.15 \\ -\mathrm{b} / \mathrm{H}=0.20 & - \text { - }-\mathrm{b} / \mathrm{H}=0.20\end{array}$

(b)

Figure 16: Continued. 


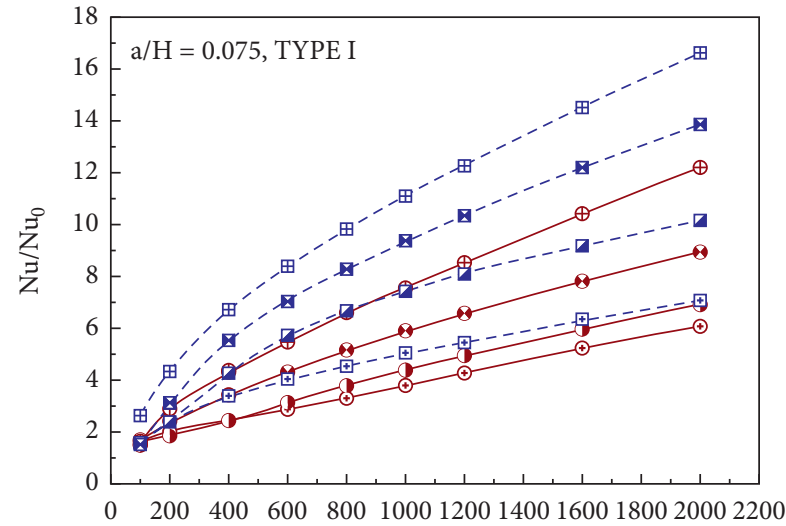

$\operatorname{Re}$

\begin{tabular}{|c|c|}
\hline V-Downstream : & V-Upstream : \\
\hline$-\odot \mathrm{b} / \mathrm{H}=0.05$ & - 田- b/H $=0.05$ \\
\hline$-\mathrm{c}-\mathrm{b} / \mathrm{H}=0.10$ & $-\square-b / H=0.10$ \\
\hline$-\mathrm{b} / \mathrm{H}=0.15$ & $-\mathbf{\mathbf { v }}-\mathrm{b} / \mathrm{H}=0.15$ \\
\hline$-\mathrm{b} / \mathrm{H}=0.20$ & $-\boxplus-\mathrm{b} / \mathrm{H}=0.20$ \\
\hline
\end{tabular}

(c)

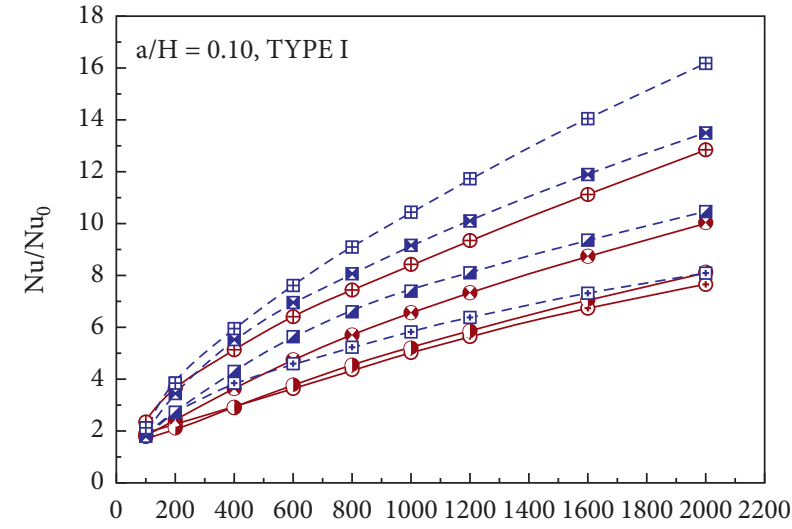

$\operatorname{Re}$

$\begin{array}{ll}\text { V-Downstream : } & \text { V-Upstream : } \\ -\odot-\mathrm{b} / \mathrm{H}=0.05 & \text {-田- } \mathrm{b} / \mathrm{H}=0.05 \\ -\mathrm{-}-\mathrm{b} / \mathrm{H}=0.10 & -\square-\mathrm{b} / \mathrm{H}=0.10 \\ \rightarrow-\mathrm{b} / \mathrm{H}=0.15 & -\mathbf{-}-\mathrm{b} / \mathrm{H}=0.15 \\ -\mathrm{b} \text { b/H }=0.20 & \text {-田 } \mathrm{b} / \mathrm{H}=0.20\end{array}$

(d)

Figure 16: $\mathrm{Nu} / \mathrm{Nu}_{0}$ vs. Re of type I for (a) $a / H=0.025$, (b) $a / H=0.05$, (c) $a / H=0.075$, and (d) $a / H=0.1$.

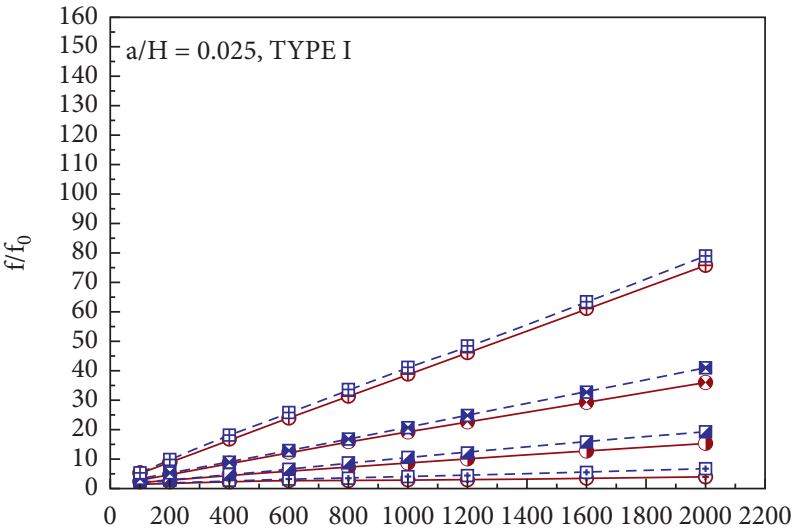

Re

V-Downstream :

$\multimap-\mathrm{b} / \mathrm{H}=0.05$

$-\mathrm{b} / \mathrm{H}=0.10$

- $\mathrm{b} / \mathrm{H}=0.15$

- $\mathrm{b} / \mathrm{H}=0.20$
V-Upstream :

$-\square-\mathrm{b} / \mathrm{H}=0.10$

$-\mathbf{-}-\mathrm{b} / \mathrm{H}=0.15$

- $\rightarrow-\mathrm{b} / \mathrm{H}=0.20$

(a)
- $⿴-\mathrm{b} / \mathrm{H}=0.05$

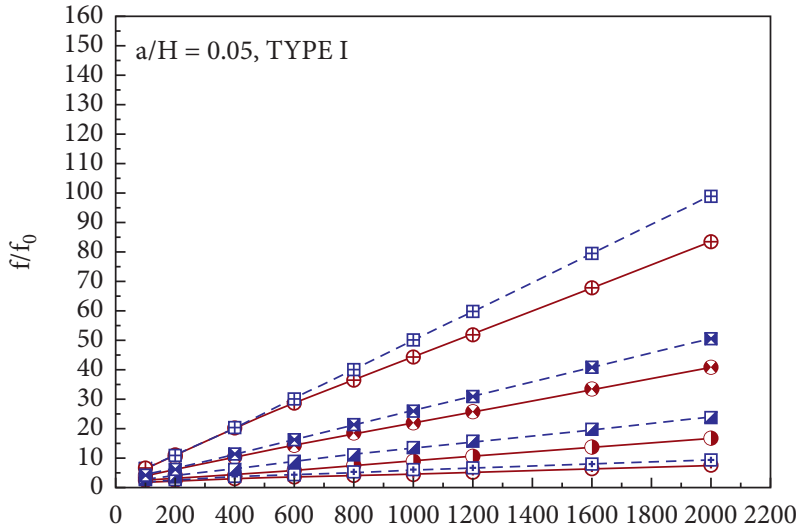

$\operatorname{Re}$

V-Downstream :

V-Upstream :

$-\odot-\mathrm{b} / \mathrm{H}=0.05$

- $\rightarrow-\mathrm{b} / \mathrm{H}=0.05$

$-\mathrm{b} / \mathrm{H}=0.10$

$-\square-\mathrm{b} / \mathrm{H}=0.10$

- $\mathrm{b} / \mathrm{H}=0.15$

$-\mathbf{\square}-\mathrm{b} / \mathrm{H}=0.15$

- $\mathrm{b} / \mathrm{H}=0.20$

(b)

Figure 17: Continued. 


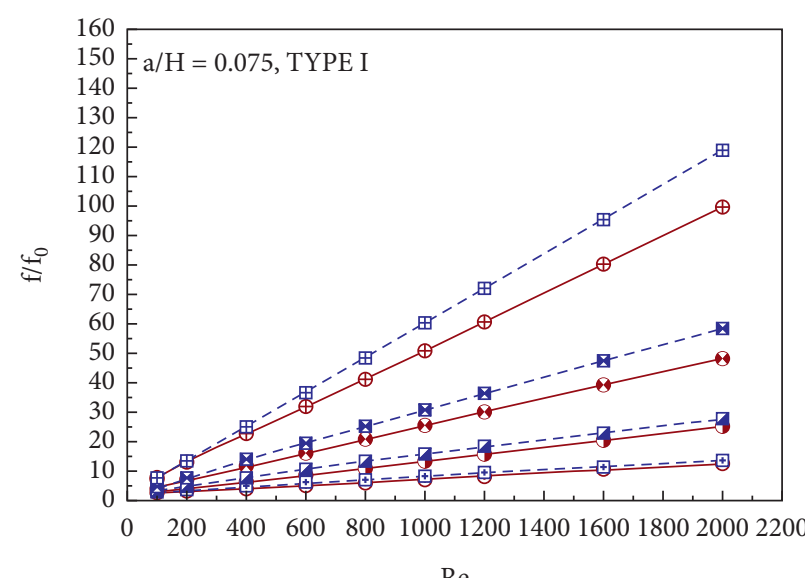

$\operatorname{Re}$

V-Downstream :

$-\odot-\mathrm{b} / \mathrm{H}=0.05$

- $\mathrm{b} / \mathrm{H}=0.10$

- $\mathrm{b} / \mathrm{H}=0.15$

- $\mathrm{b} / \mathrm{H}=0.20$

(c)

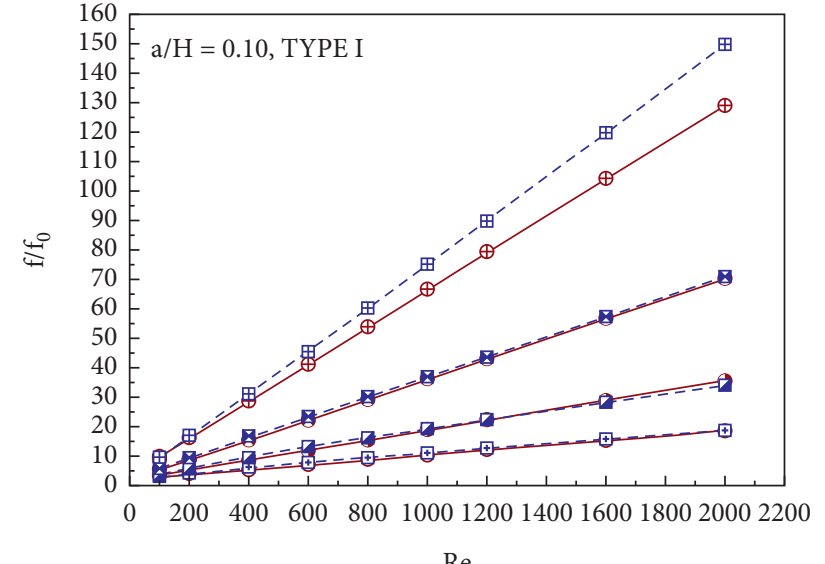

V-Downstream :

V-Upstream :

$-\odot-\mathrm{b} / \mathrm{H}=0.05$

- $\rightarrow-\mathrm{b} / \mathrm{H}=0.05$

$-\mathrm{b} / \mathrm{H}=0.10$

$-\mathrm{b} / \mathrm{H}=0.10$

- $\mathrm{b} / \mathrm{H}=0.15$

$-\mathbf{\square}-\mathrm{b} / \mathrm{H}=0.15$

(4) $\mathrm{b} / \mathrm{H}=0.20$

(d)

FIgURE 17: $f / f_{0}$ vs. Re of type I for (a) $a / H=0.025$, (b) $a / H=0.05$, (c) $a / H=0.075$, and (d) $a / H=0.1$.

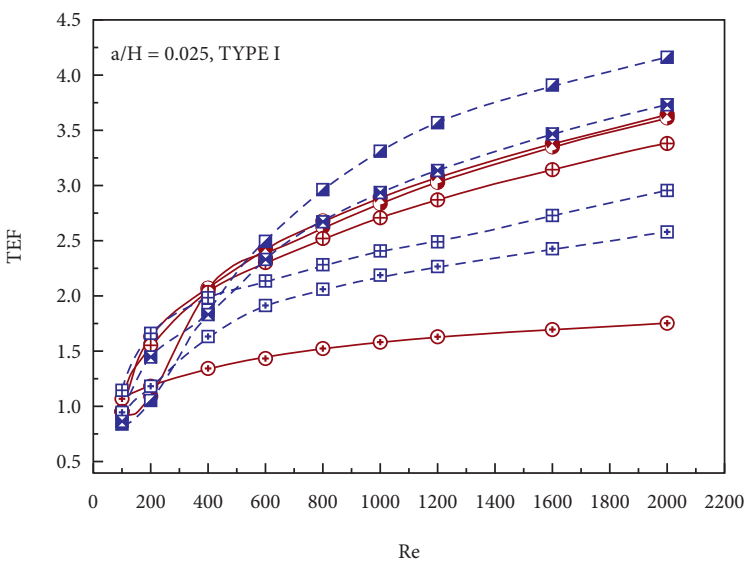

$\operatorname{Re}$

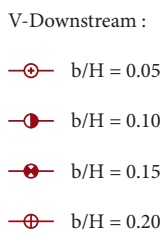

V-Downstream :
V-Upstream :

- $-\mathrm{⿴}-\mathrm{b} / \mathrm{H}=0.05$

$-\square-\mathrm{b} / \mathrm{H}=0.10$

$-\mathbf{-}-\mathrm{b} / \mathrm{H}=0.15$

- $\boxplus-\mathrm{b} / \mathrm{H}=0.20$

(a)

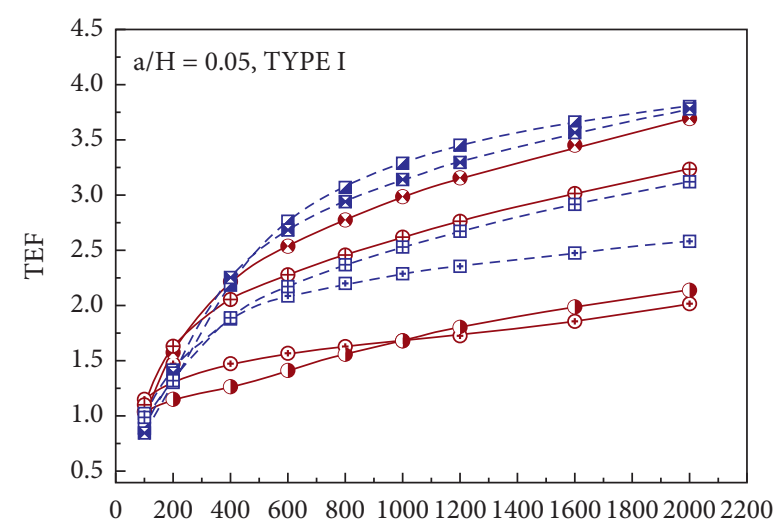

$\mathrm{Re}$

V-Downstream :

V-Upstream :

$-\mathrm{b} / \mathrm{H}=0.05$
$-\mathrm{b} / \mathrm{H}=0.10$
$\rightarrow \mathrm{b} / \mathrm{H}=0.15$
$\rightarrow \mathrm{b} / \mathrm{H}=0.20$

- - - b/H $=0.05$

- - $\mathrm{b} / \mathrm{H}=0.10$

- $\mathbf{-}-\mathrm{b} / \mathrm{H}=0.15$

- $⿴ 囗 \mathrm{~b} / \mathrm{H}=0.20$

(b)

Figure 18: Continued. 


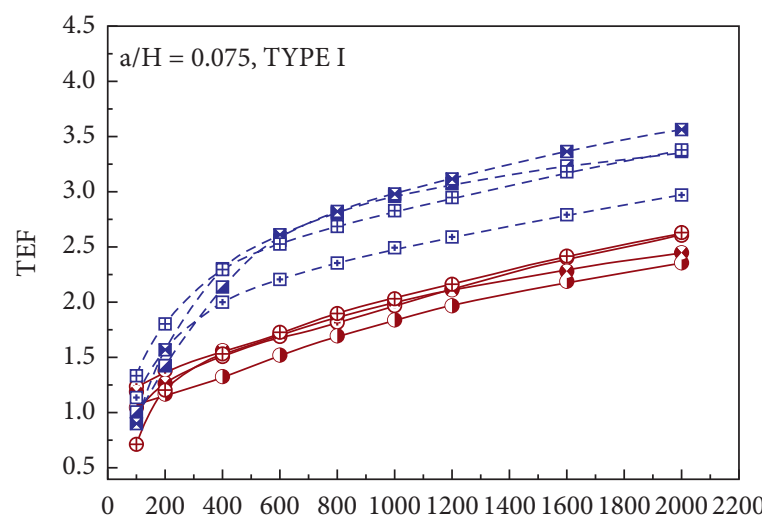

$\mathrm{Re}$

$$
\begin{aligned}
& \text { V-Downstream : } \\
& -\odot-\mathrm{b} / \mathrm{H}=0.05 \\
& -\mathrm{b} / \mathrm{H}=0.10 \\
& -\mathrm{b} / \mathrm{H}=0.15 \\
& -\mathrm{b} / \mathrm{H}=0.20
\end{aligned}
$$

(c)

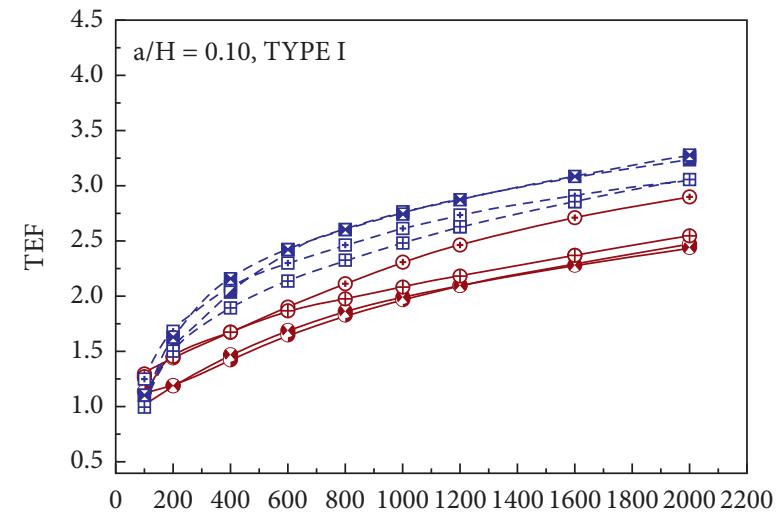

$\operatorname{Re}$

$$
\begin{array}{ll}
\text { V-Downstream : } & \text { V-Upstream : } \\
-\odot-\mathrm{b} / \mathrm{H}=0.05 & - \text { - }-\mathrm{b} / \mathrm{H}=0.05 \\
\rightarrow-\mathrm{b} / \mathrm{H}=0.10 & -\mathbf{\square}-\mathrm{b} / \mathrm{H}=0.10 \\
\rightarrow-\mathrm{b} / \mathrm{H}=0.15 & -\mathbf{\square}-\mathrm{b} / \mathrm{H}=0.15 \\
\rightarrow \mathrm{b} / \mathrm{H}=0.20 & - \text { - }-\mathrm{b} / \mathrm{H}=0.20
\end{array}
$$

(d)

Figure 18: TEF vs. Re of type I for (a) $a / H=0.025$, (b) $a / H=0.05$, (c) $a / H=0.075$, and (d) $a / H=0.1$.

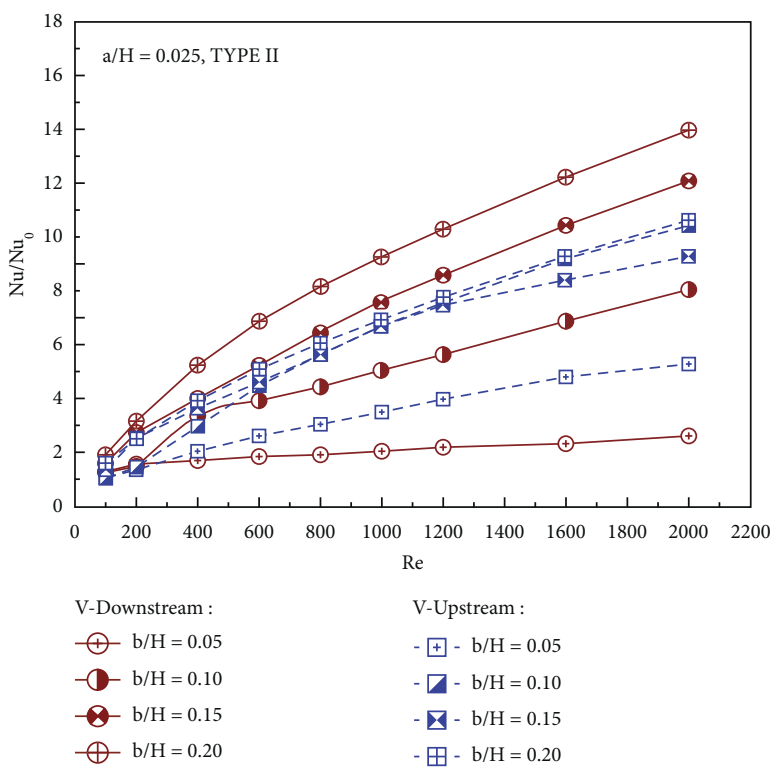

(a)

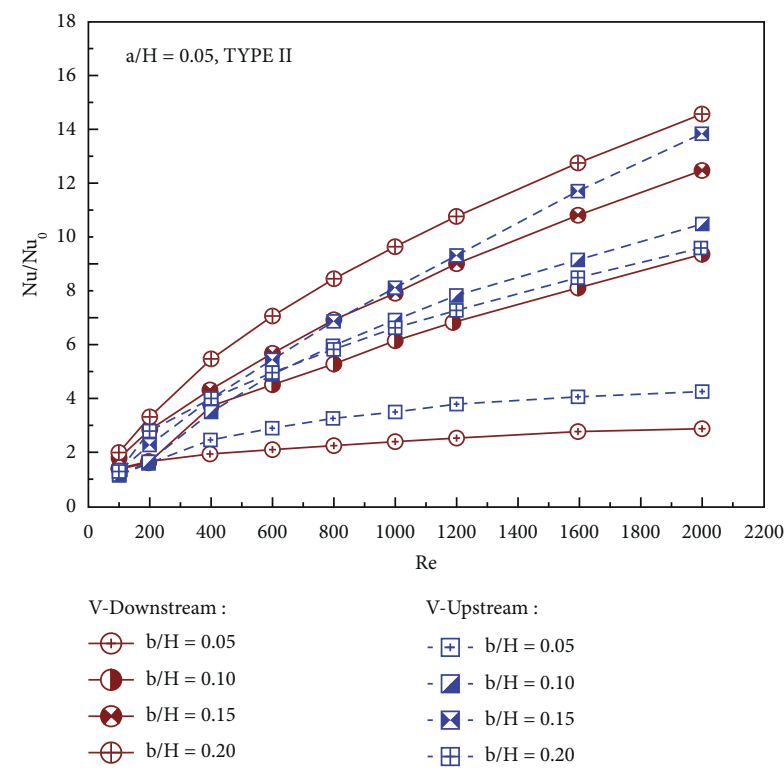

(b)

Figure 19: Continued. 


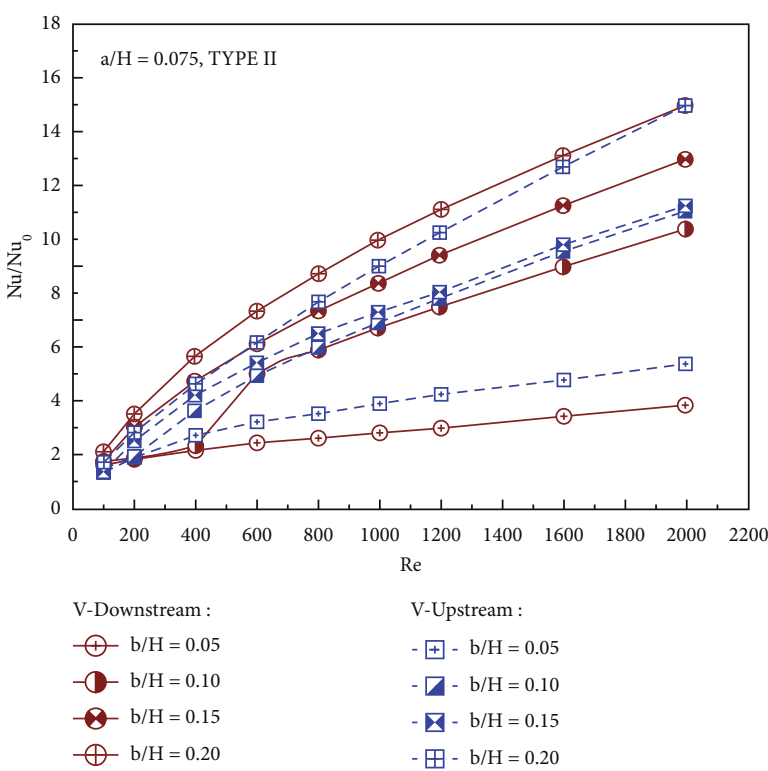

(c)

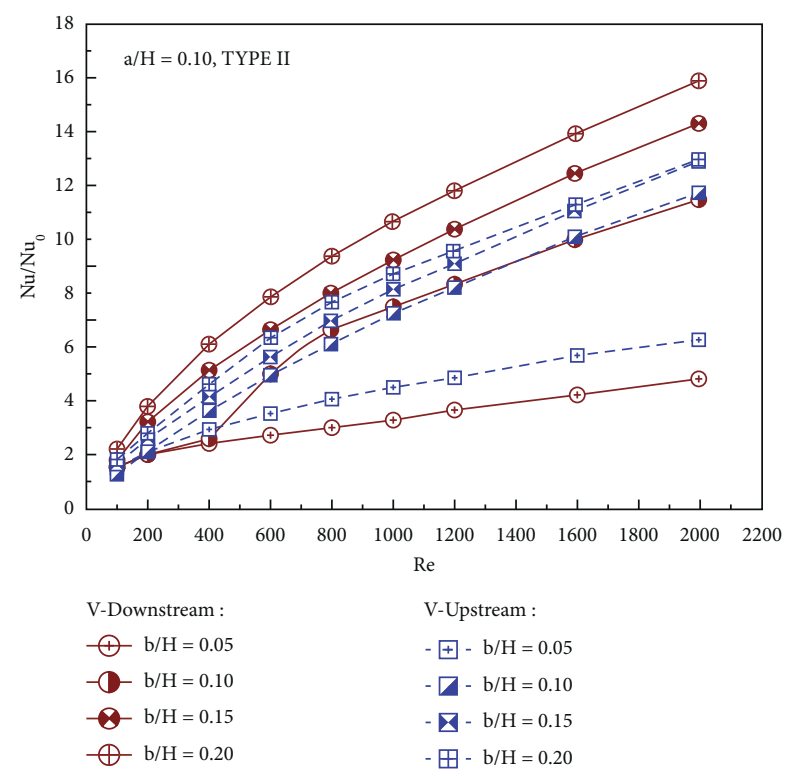

(d)

Figure 19: $\mathrm{Nu} / \mathrm{Nu}_{0}$ vs. Re of type II for (a) $a / H=0.025$, (b) $a / H=0.05$, (c) $a / H=0.075$, and (d) $a / H=0.1$.

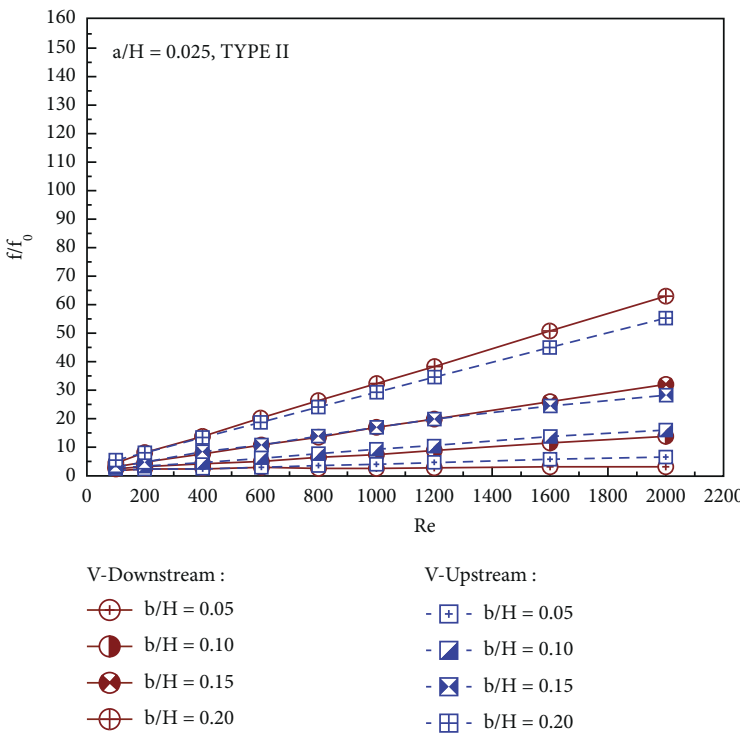

(a)

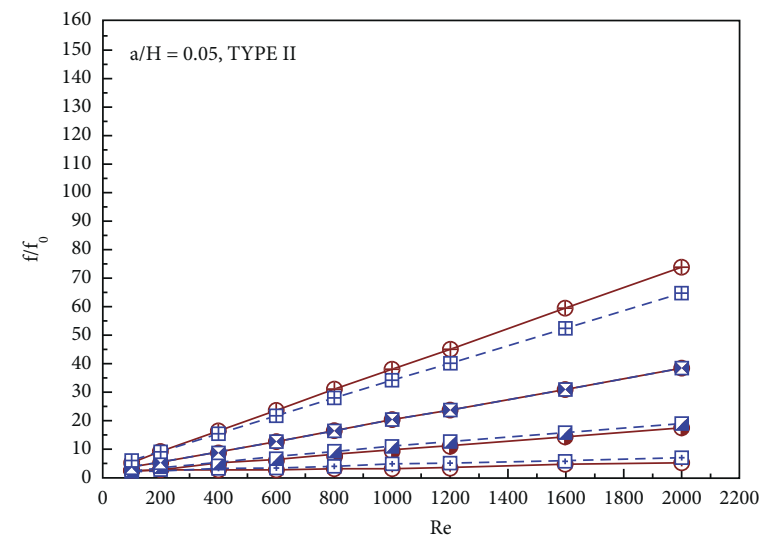

V-Downstream:
(1) $\mathrm{b} / \mathrm{H}=0.05$
$\mathrm{~b} / \mathrm{H}=0.10$
$\mathrm{~b} / \mathrm{H}=0.15$
$\mathrm{~b} / \mathrm{H}=0.20$

V-Upstream :

- $\boxplus-\mathrm{b} / \mathrm{H}=0.05$

- $\mathrm{Z}-\mathrm{b} / \mathrm{H}=0.10$

- $\boldsymbol{\nabla}-\mathrm{b} / \mathrm{H}=0.15$

- $\boxplus-\mathrm{b} / \mathrm{H}=0.20$

(b)

Figure 20: Continued. 


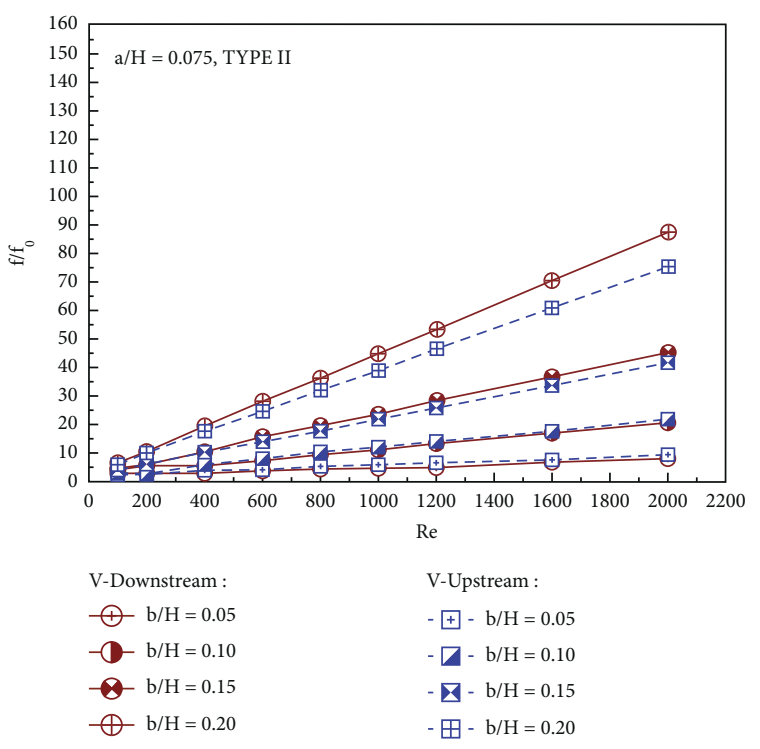

(c)

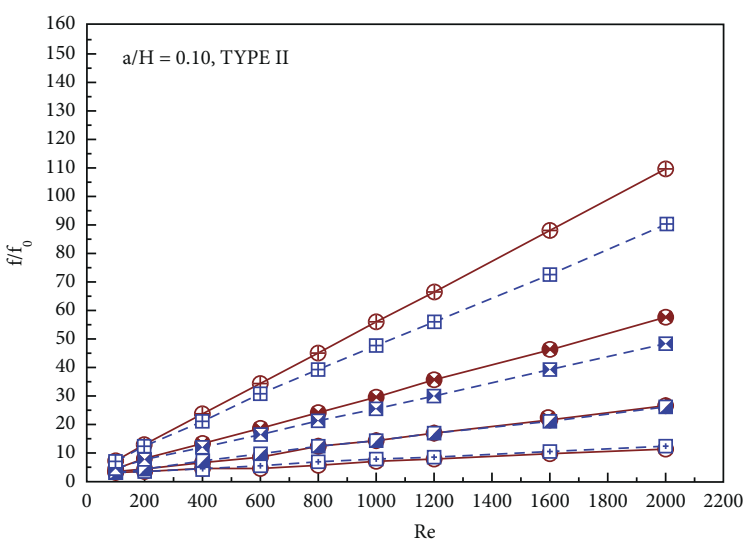

V-Downstream :

(I) $\mathrm{b} / \mathrm{H}=0.05$

$-\mathrm{b} / \mathrm{H}=0.10$

- $\mathrm{b} / \mathrm{H}=0.15$

(1) $\mathrm{b} / \mathrm{H}=0.20$
V-Upstream :

- $\emptyset-\mathrm{b} / \mathrm{H}=0.05$

- $\boldsymbol{Z}-\mathrm{b} / \mathrm{H}=0.10$

- $\boldsymbol{\nabla}-\mathrm{b} / \mathrm{H}=0.15$

- 田- b/H $=0.20$

(d)

Figure 20: $f / f_{0}$ vs. Re of type II for (a) $a / H=0.025$, (b) $a / H=0.05$, (c) $a / H=0.075$, and (d) $a / H=0.1$.

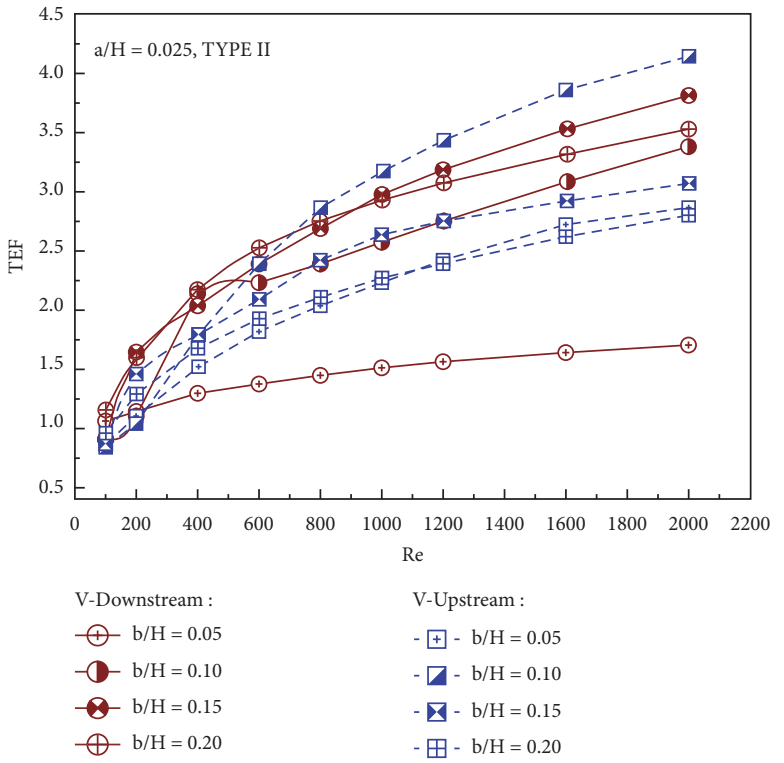

(a)

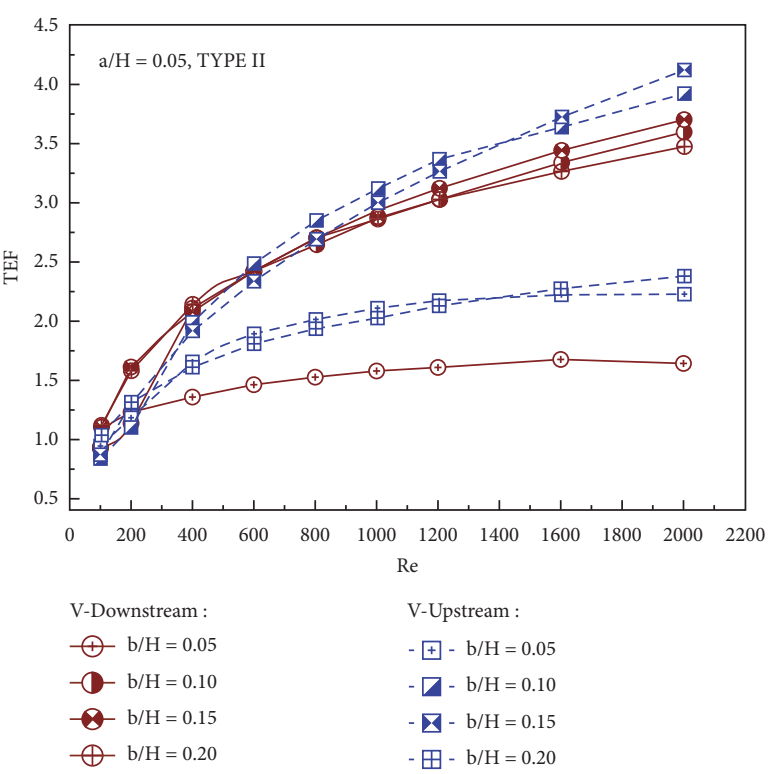

(b)

FIGURe 21: Continued. 


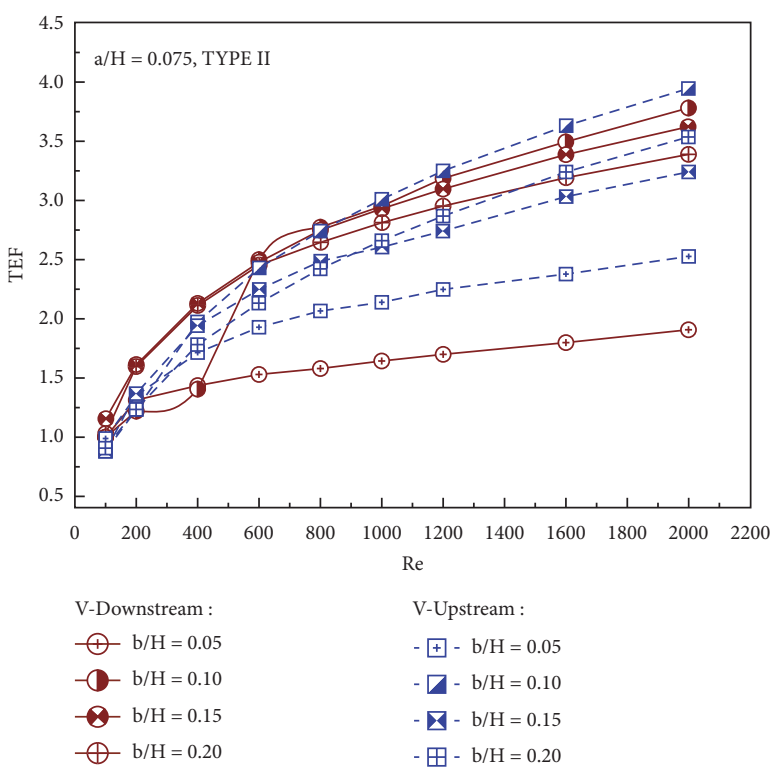

(c)

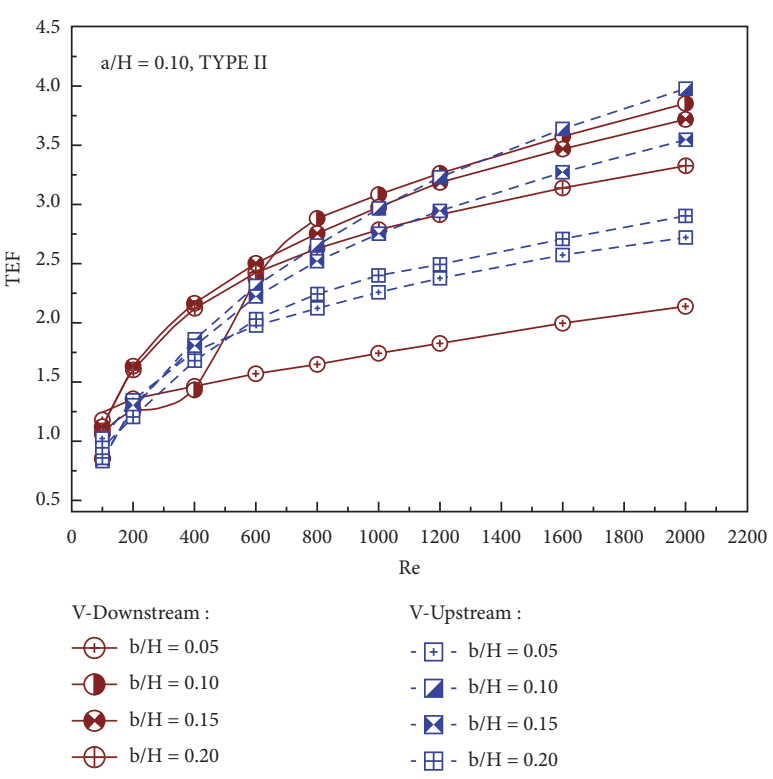

(d)

Figure 21: TEF vs. Re of type II for (a) $a / H=0.025$, (b) $a / H=0.05$, (c) $a / H=0.075$, and (d) $a / H=0.1$.

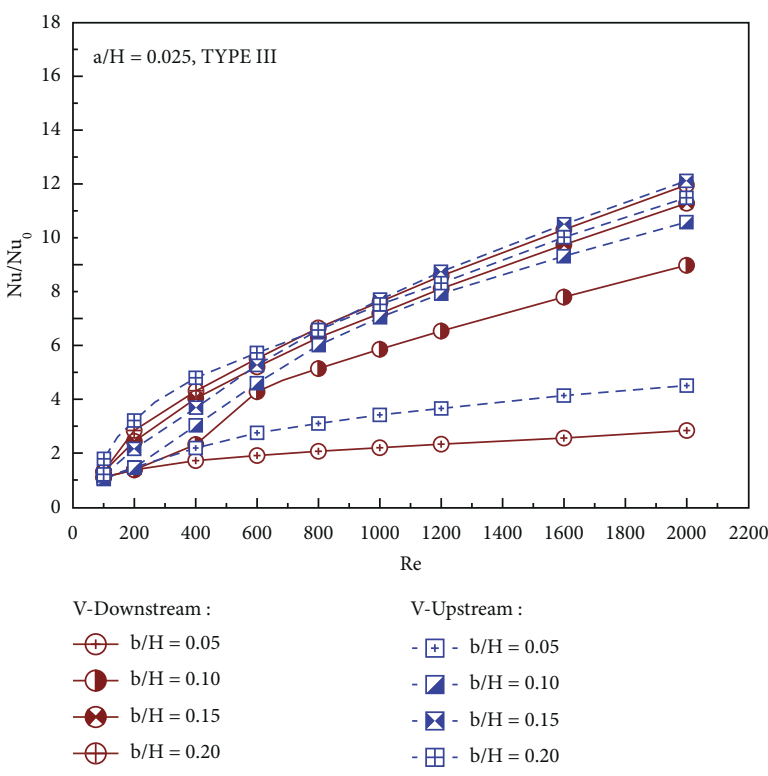

(a)

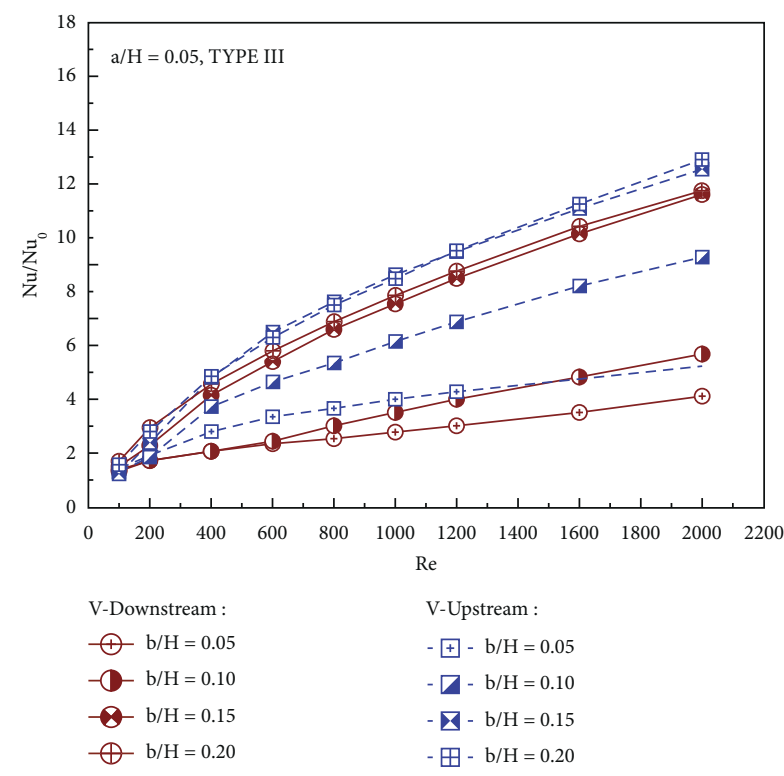

(b)

Figure 22: Continued. 


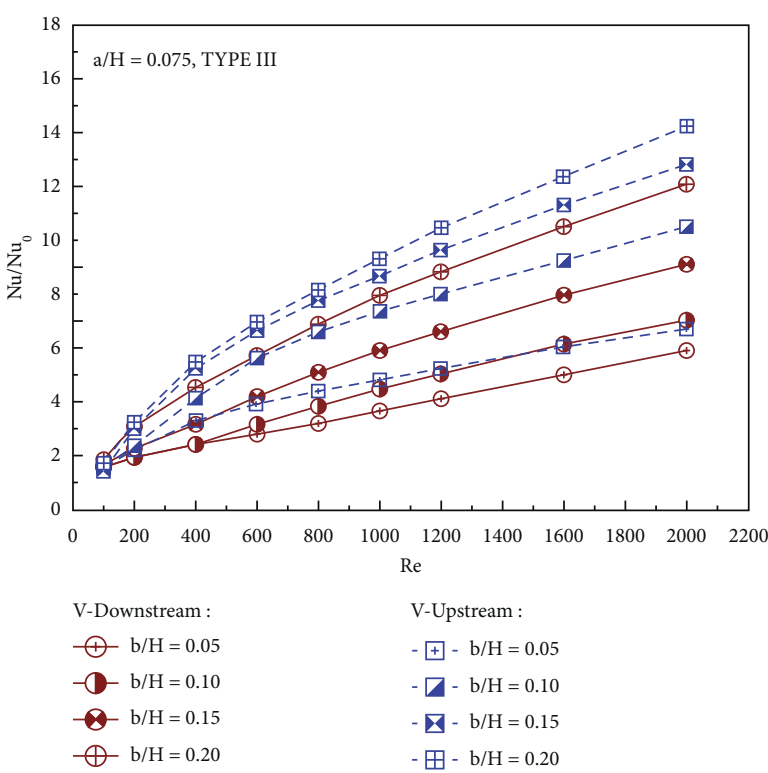

(c)

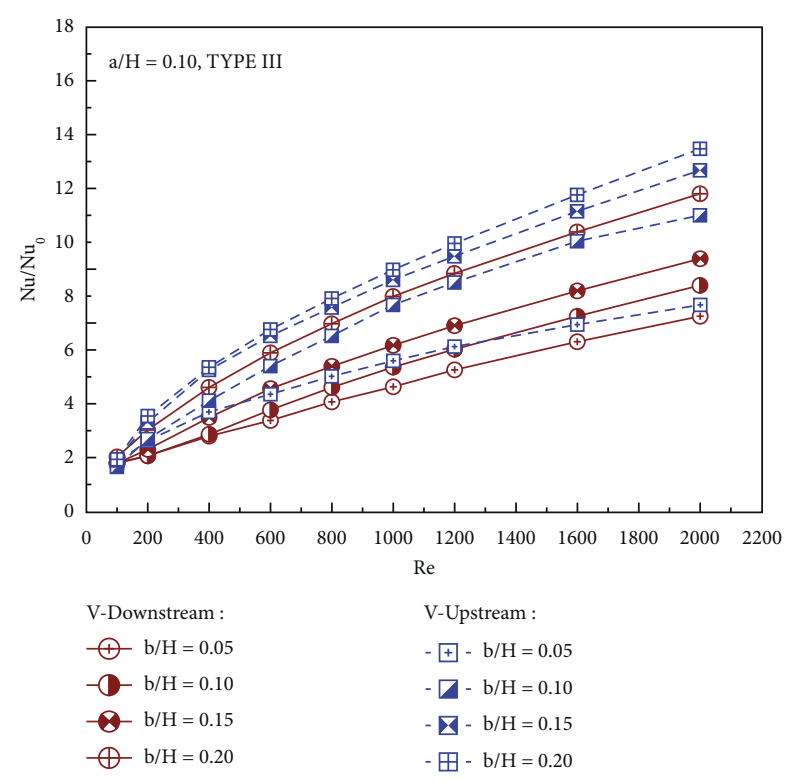

(d)

Figure 22: $\mathrm{Nu} / \mathrm{Nu}_{0}$ vs. Re of type III for (a) $a / H=0.025$, (b) $a / H=0.05$, (c) $a / H=0.075$, and (d) $a / H=0.1$.

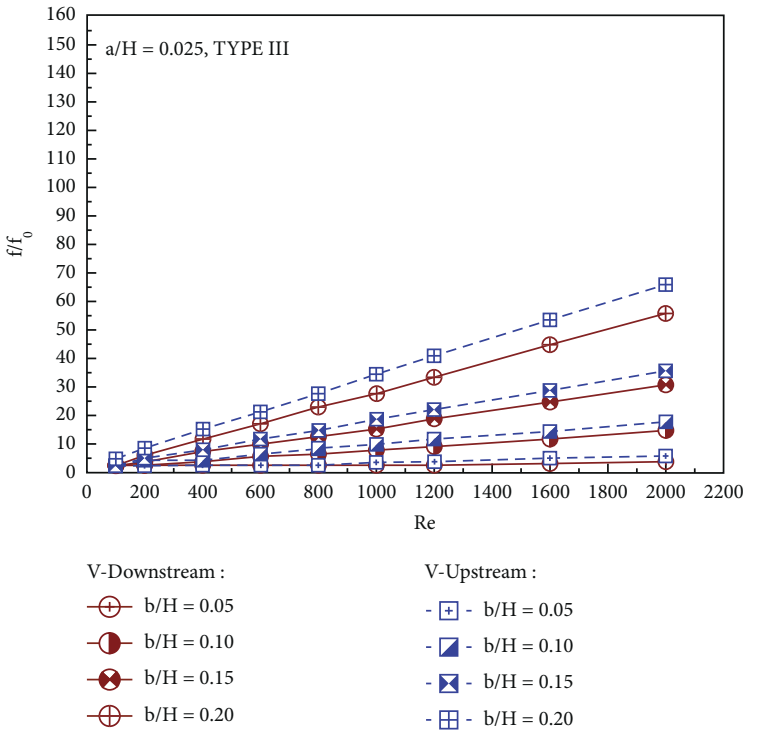

(a)

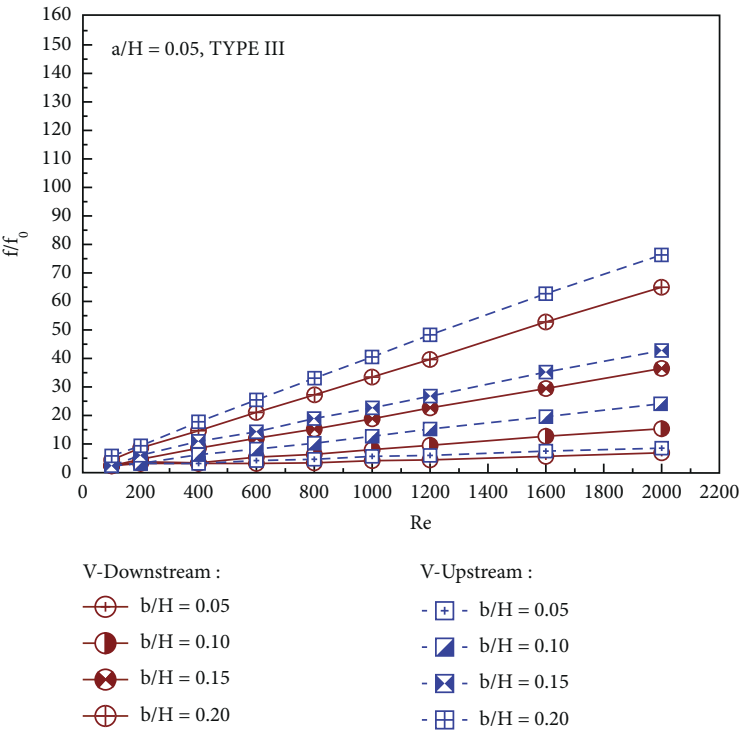

(b)

FIgURE 23: Continued. 


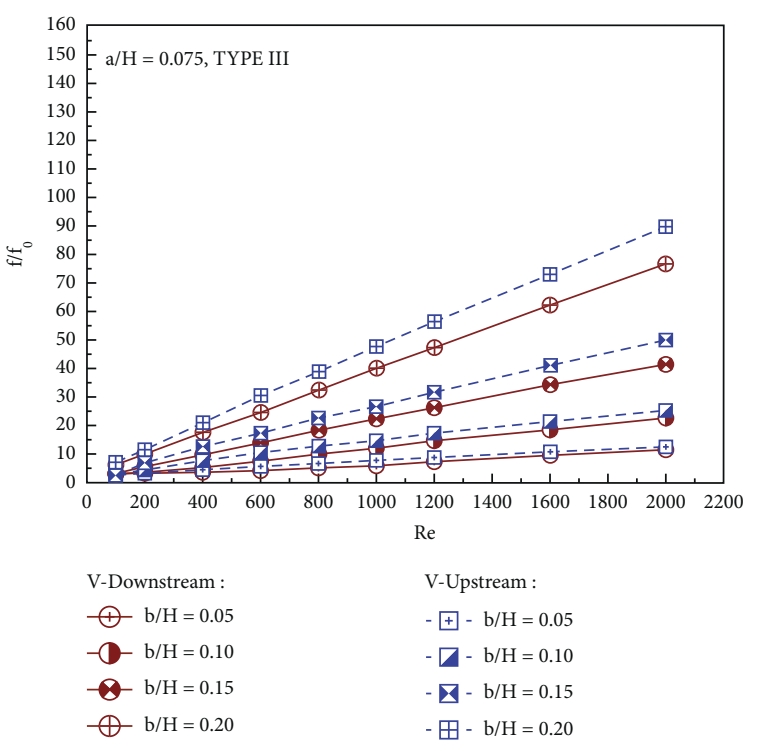

(c)

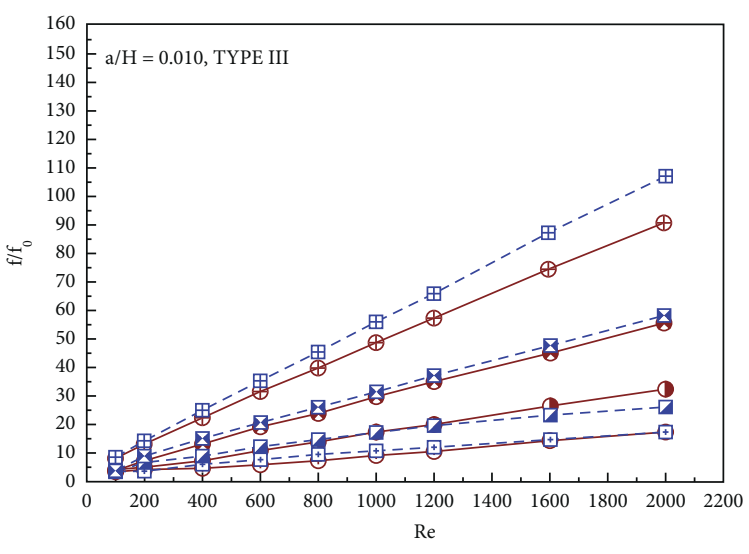

V-Downstream :

(1) $\mathrm{b} / \mathrm{H}=0.05$

$-\mathrm{b} / \mathrm{H}=0.10$

b/H $=0.15$

(1) $\mathrm{b} / \mathrm{H}=0.20$
V-Upstream :

- $¥-\mathrm{b} / \mathrm{H}=0.05$

- $\square-\mathrm{b} / \mathrm{H}=0.10$

- $\boldsymbol{\nabla}-\mathrm{b} / \mathrm{H}=0.15$

- 田- b/H $=0.20$

(d)

FIGURE 23: $f / f_{0}$ vs. Re of type III for (a) $a / H=0.025$, (b) $a / H=0.05$, (c) $a / H=0.075$, and (d) $a / H=0.1$.

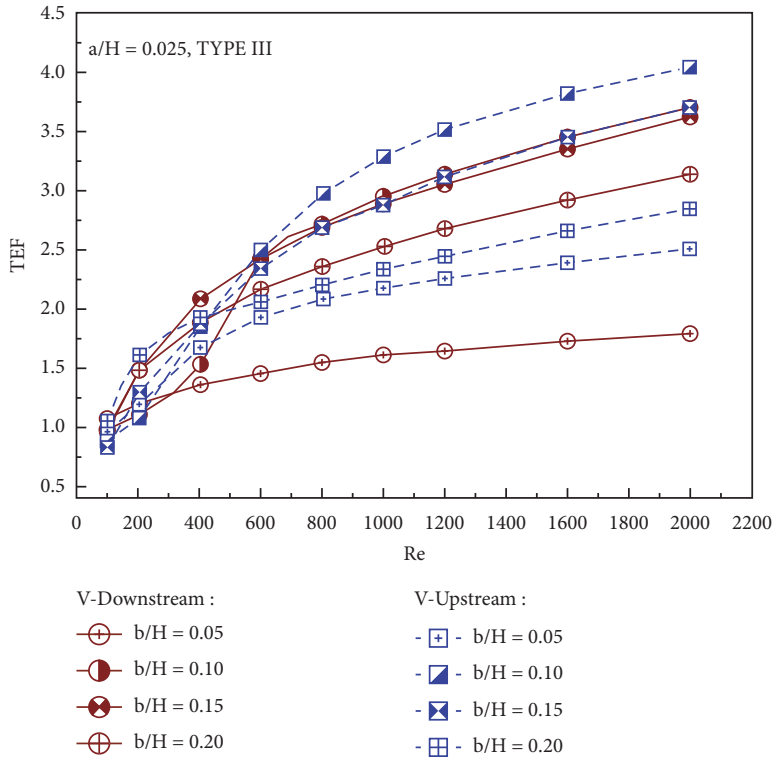

(a)

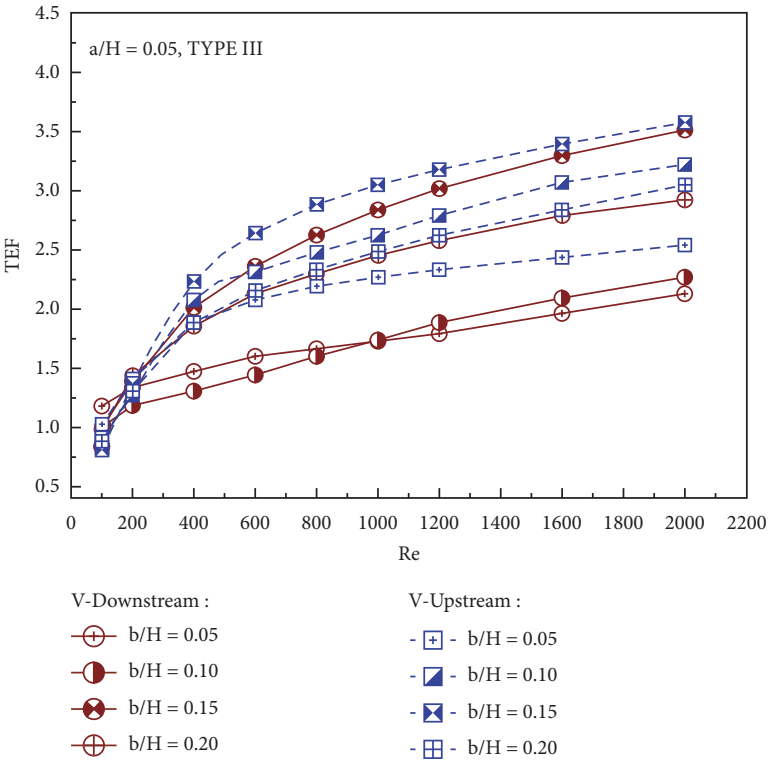

(b)

Figure 24: Continued. 


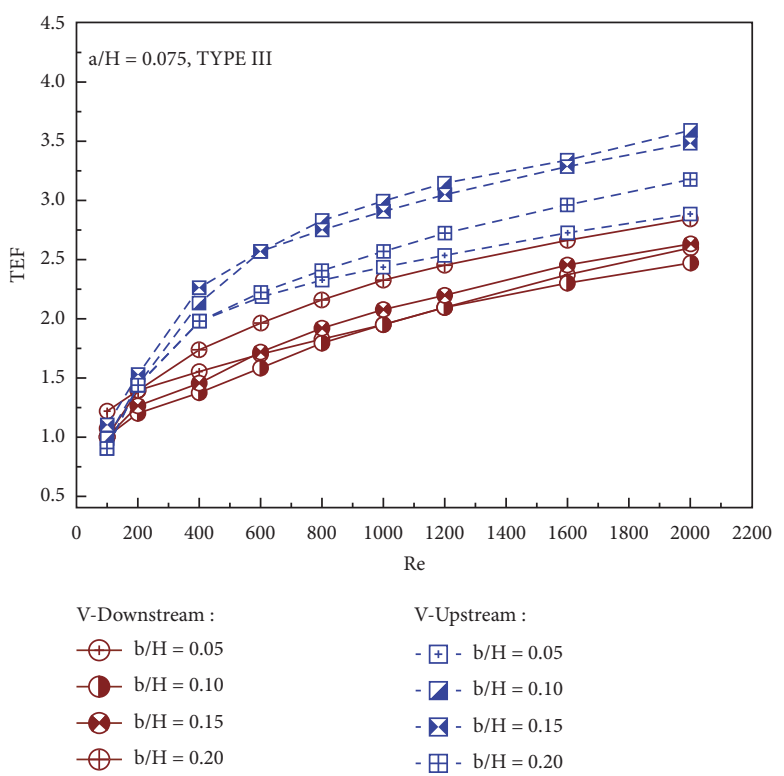

(c)

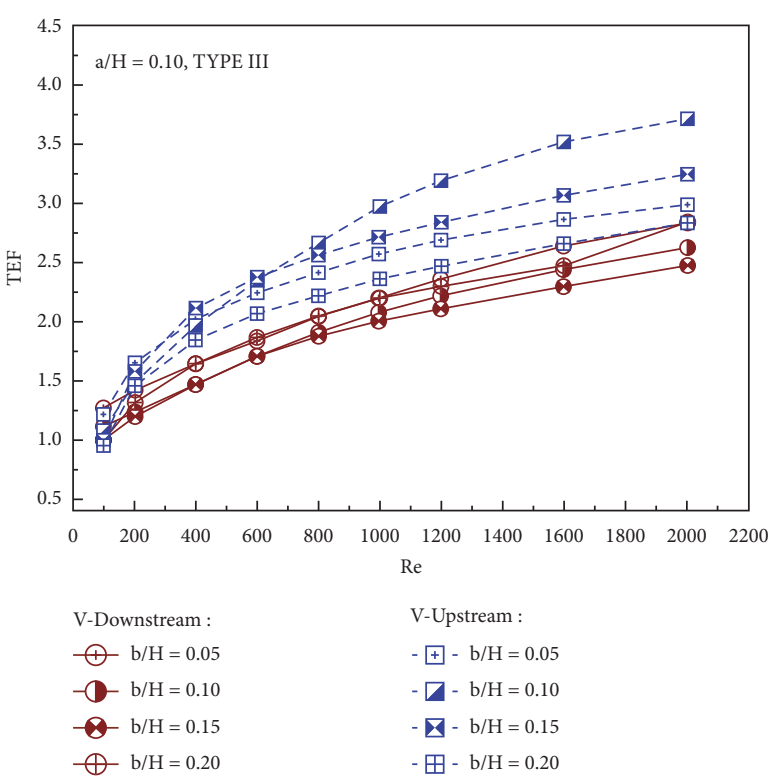

(d)

Figure 24: TEF vs. Re of type III for (a) $a / H=0.025$, (b) $a / H=0.05$, (c) $a / H=0.075$, and (d) $a / H=0.1$.

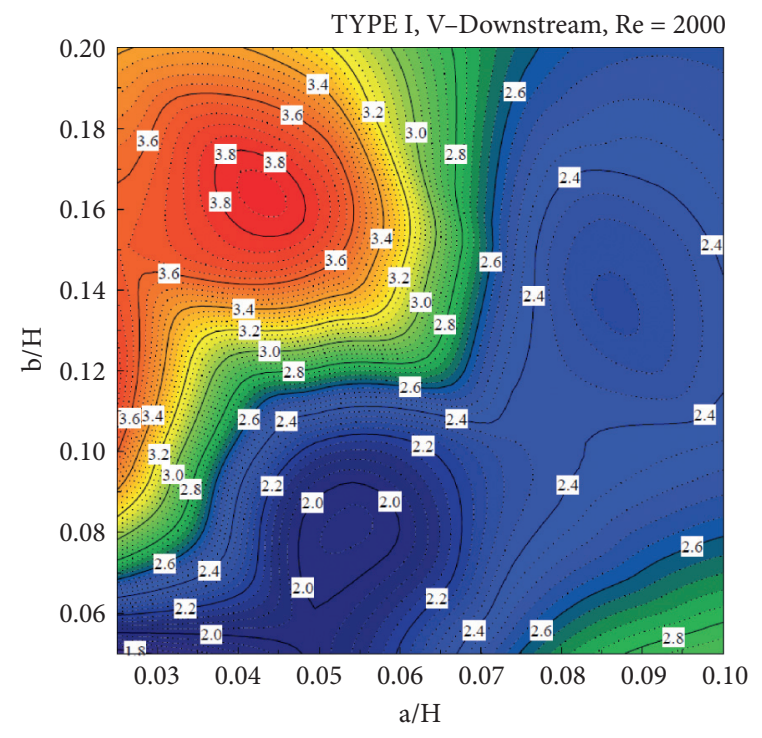

(a)

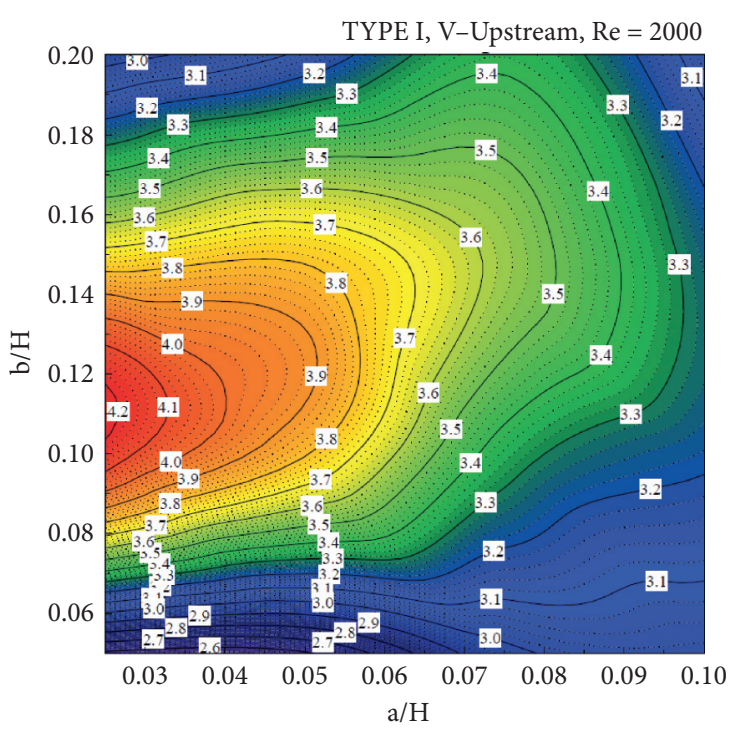

(b)

Figure 25: TEF contour of type I with various $a / H$ and $b / H$ for (a) V-downstream and (b) V-upstream. 


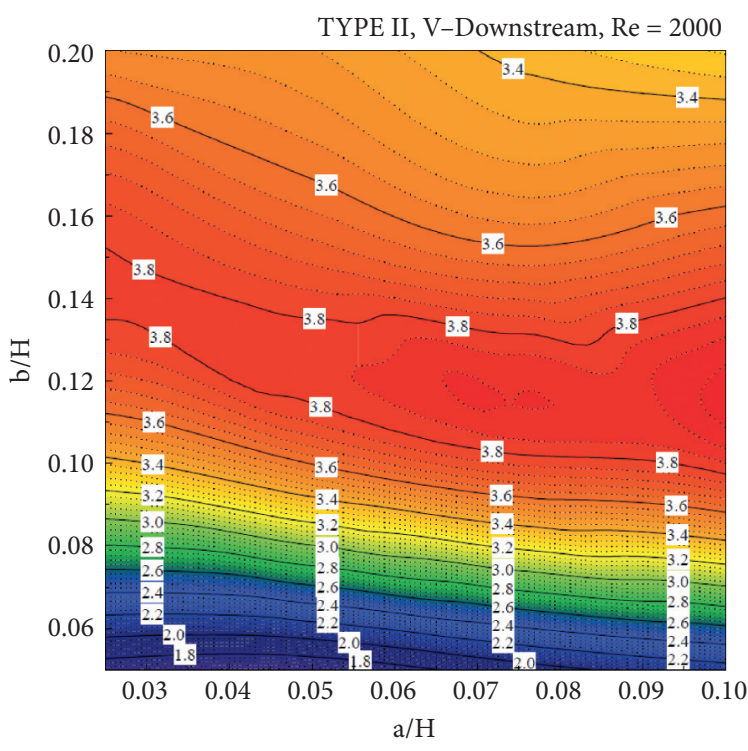

(a)

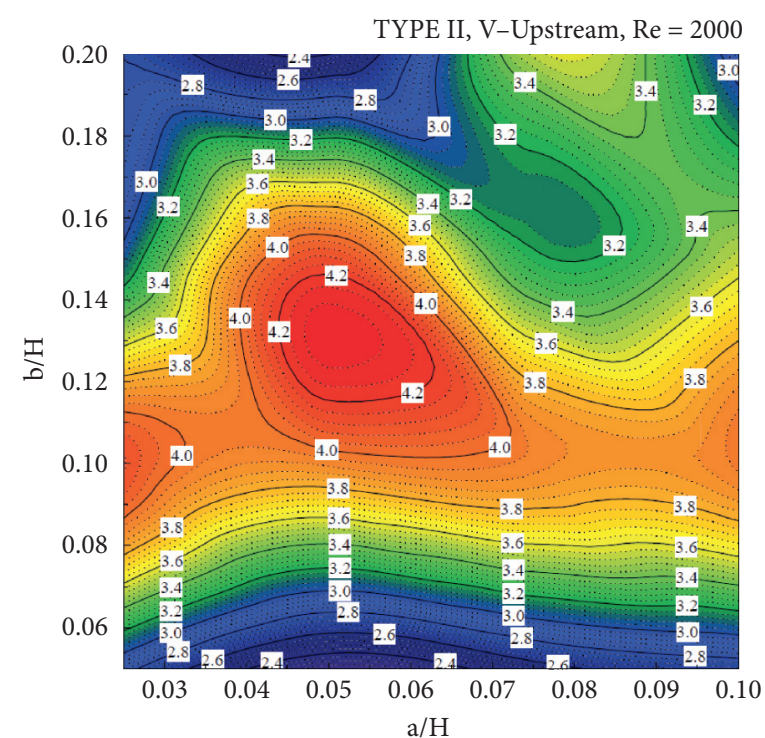

(b)

Figure 26: TEF contour of type II with various $a / H$ and $b / H$ for (a) V-downstream and (b) V-upstream.

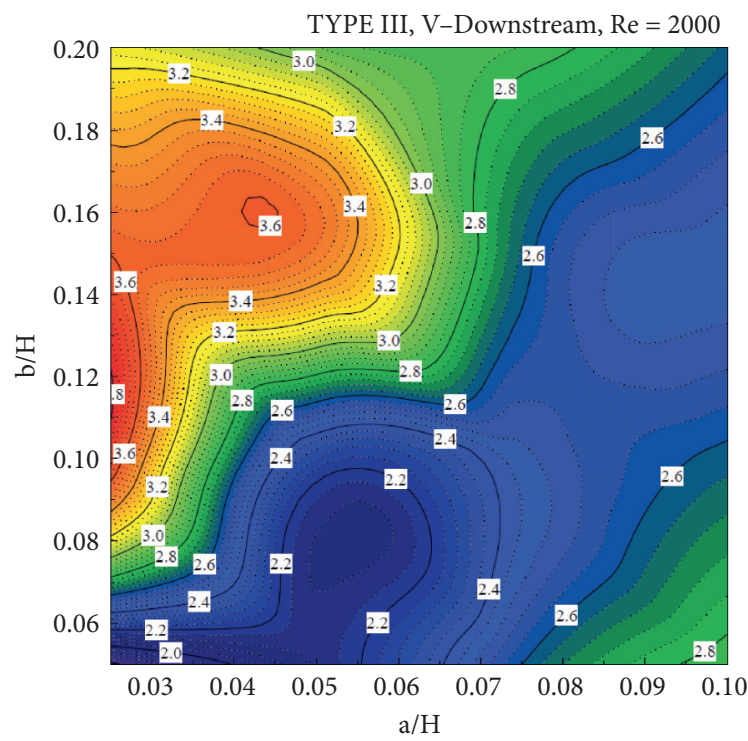

(a)

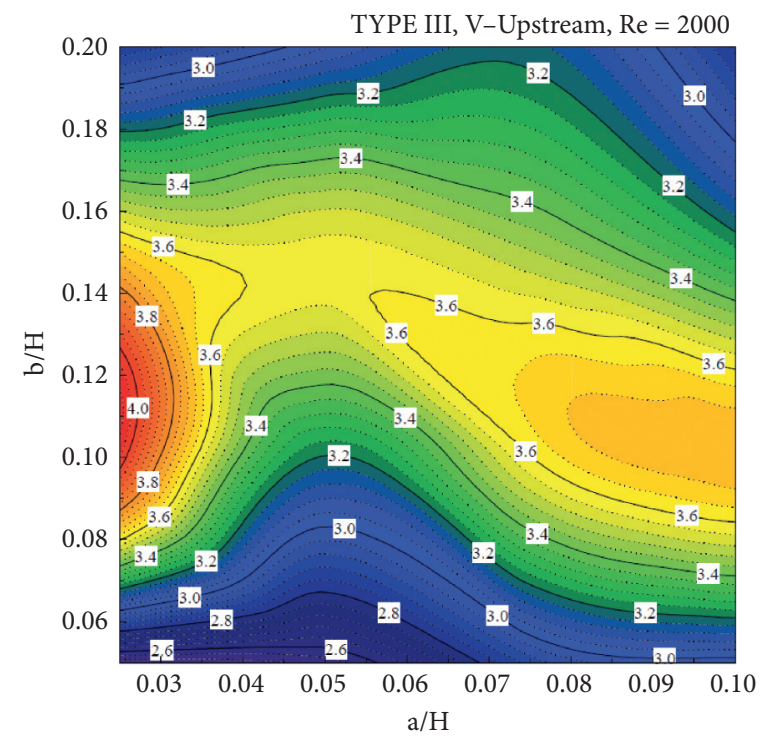

(b)

FIGURE 27: TEF contour of type III with various $a / H$ and $b / H$ for (a) V-downstream and (b) V-upstream. 

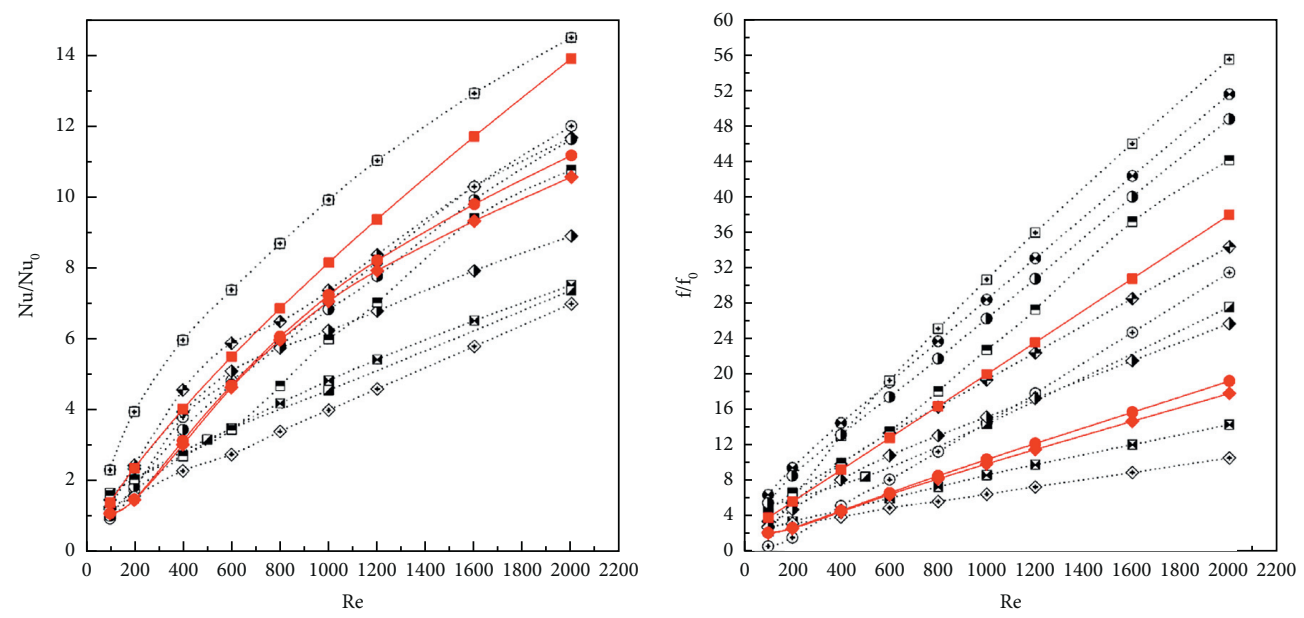

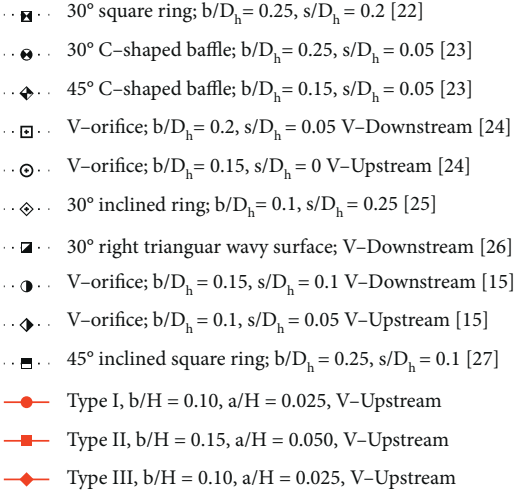

(a)
. . $30^{\circ}$ square ring; $\mathrm{b} / \mathrm{D}_{\mathrm{h}}=0.25, \mathrm{~s} / \mathrm{D}_{\mathrm{h}}=0.2[22]$

. . $30^{\circ} \mathrm{C}$-shaped baffle; $\mathrm{b} / \mathrm{D}_{\mathrm{h}}=0.25, \mathrm{~s} / \mathrm{D}_{\mathrm{h}}=0.05[23]$

4. $45^{\circ} \mathrm{C}$-shaped baffle; $\mathrm{b} / \mathrm{D}_{\mathrm{h}}=0.15, \mathrm{~s} / \mathrm{D}_{\mathrm{h}}=0.05$ [23]

๑. V V-orifice; $\mathrm{b} / \mathrm{D}_{\mathrm{h}}=0.2, \mathrm{~s} / \mathrm{D}_{\mathrm{h}}=0.05 \mathrm{~V}$-Downstream [24]

๑. . V-orifice; $\mathrm{b} / \mathrm{D}_{\mathrm{h}}=0.15, \mathrm{~s} / \mathrm{D}_{\mathrm{h}}=0 \mathrm{~V}$-Upstream [24]

๑. . $30^{\circ}$ inclined ring; $\mathrm{b} / \mathrm{D}_{\mathrm{h}}=0.1, \mathrm{~s} / \mathrm{D}_{\mathrm{h}}=0.25$ [25]

घ $30^{\circ}$ right trianguar wavy surface; $\mathrm{V}-$ Downstream [26]

- . V-orifice; $\mathrm{b} / \mathrm{D}_{\mathrm{h}}=0.15, \mathrm{~s} / \mathrm{D}_{\mathrm{h}}=0.1 \mathrm{~V}$-Downstream [15]

\. V-orifice; $\mathrm{b} / \mathrm{D}_{\mathrm{h}}=0.1, \mathrm{~s} / \mathrm{D}_{\mathrm{h}}=0.05 \mathrm{~V}$-Upstream [15]

... $45^{\circ}$ inclined square ring; $\mathrm{b} / \mathrm{D}_{\mathrm{h}}=0.25, \mathrm{~s} / \mathrm{D}_{\mathrm{h}}=0.1$ [27]

$\longrightarrow$ Type I, b/H =0.10, a/H =0.025, V-Upstream

- Type II, b/H = 0.15, a/H = 0.050, V-Upstream

$\longrightarrow$ Type III, b/H = 0.10, a/H = 0.025, V-Upstream

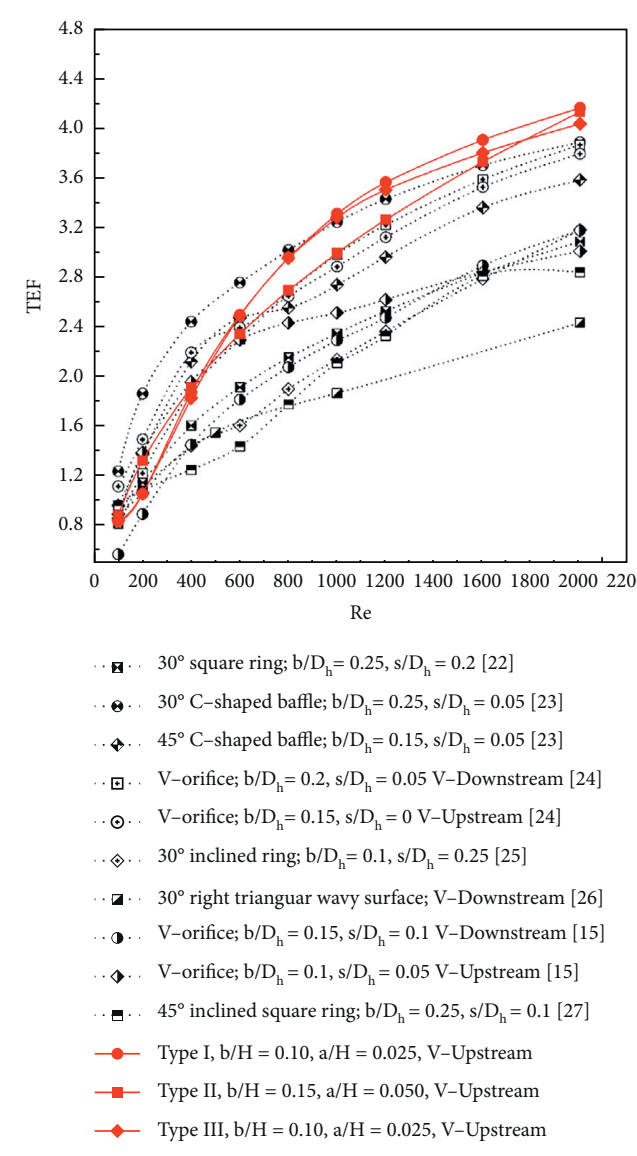

(b)

(c)

FIGURE 28: Comparison between the present results with the previous works for (a) $\mathrm{Nu} / \mathrm{Nu}_{0}$ vs. Re, (b) $f / f_{0}$ vs. Re, and (c) TEF vs. Re. 

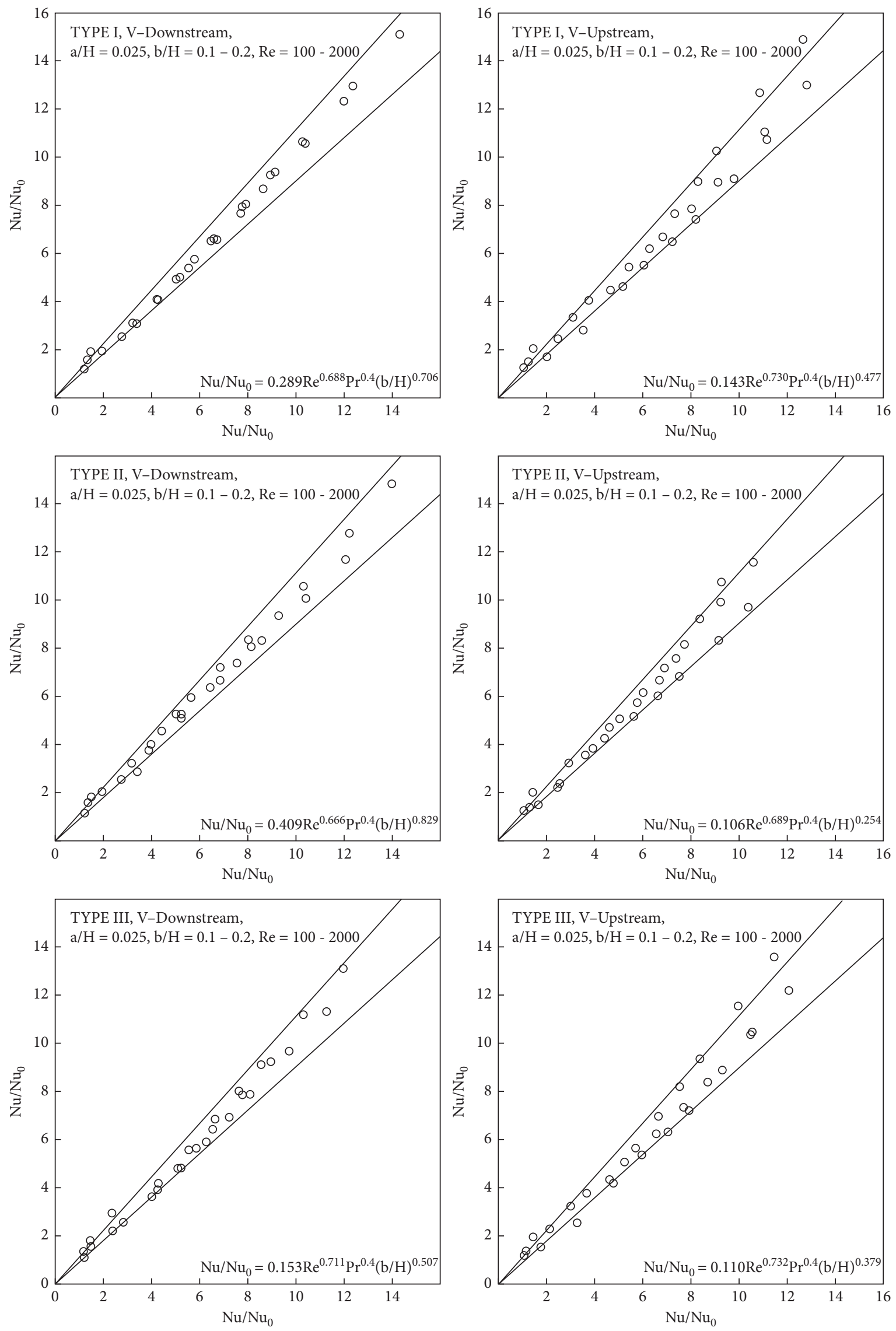

FIgURE 29: $\mathrm{Nu} / \mathrm{Nu}_{0}$ correlations for various DVR types. 

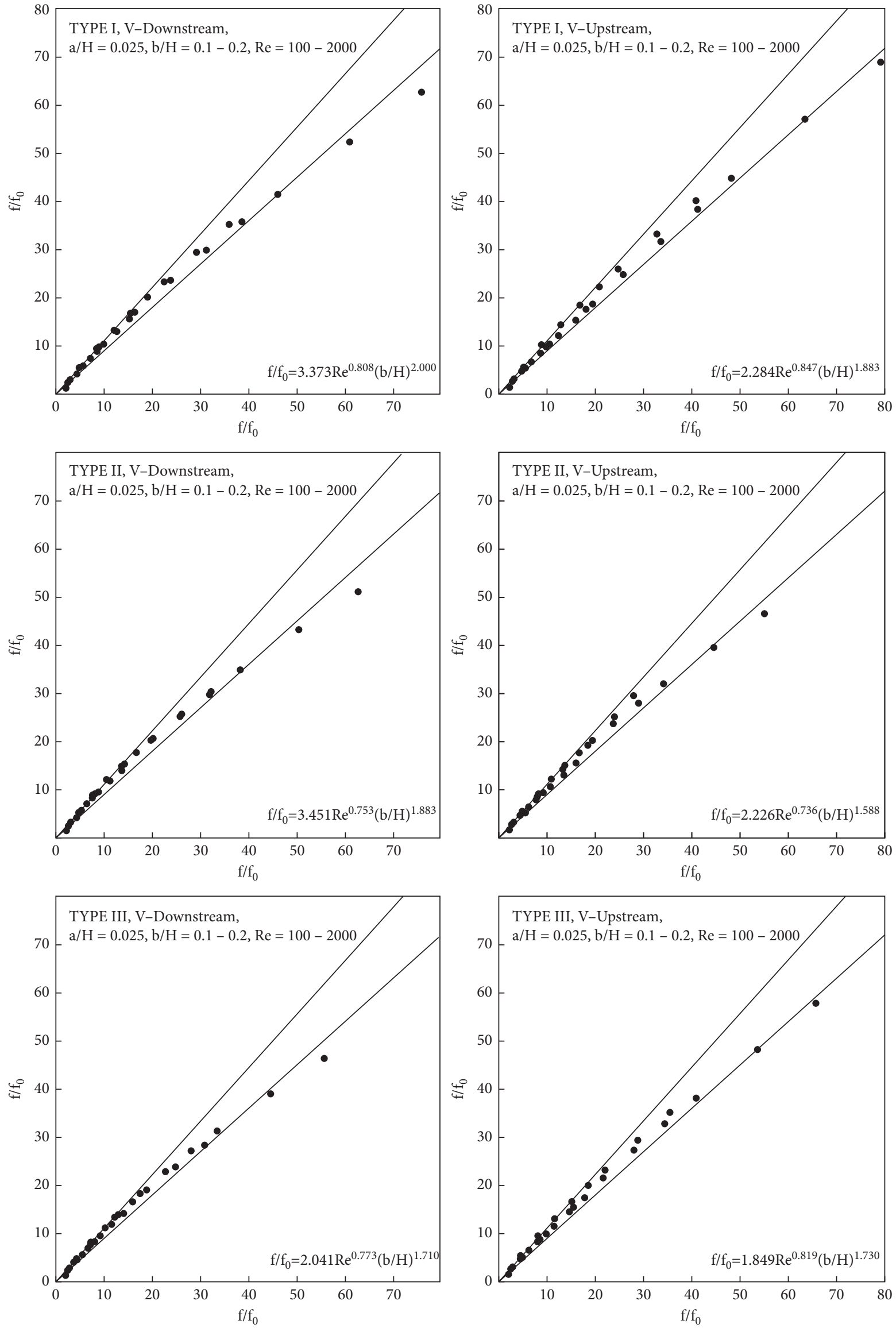

FIGURE 30: $f / f_{0}$ correlations for various DVR types. 
$\mathrm{Re}=2000$, the DVR with $a / H=0.025,0.05,0.075$, and 0.1 gives the maximum TEF around 4.04, 3.58, 3.60, and 3.71, respectively, at $b / H=0.10,0.15,0.10$, and 0.10 .

\section{Conclusion}

Numerical investigations on flow topologies, heat transfer configurations, and performance in the HED installed with the different DVR configurations (types I, II, and III) are reported. The DVR sizes in terms of $a / H$ and $b / H$ are considered. The $a / H$ and $b / H$ values are varied in the range around $0.025-0.1$ and $0.05-0.2$, respectively. The flow directions, $\mathrm{V}$-Downstream and $\mathrm{V}$-Upstream arrangements, in the HED inserted with the DVR are discussed. The laminar flow with the Reynolds number around 100-2000 (at the entry condition) is analyzed. The outcomes of the present research can be summarized as follows:

The longitudinal vortex streams and impinging streams in the HED can be found in all investigated cases. The longitudinal streams and impinging streams interrupt thermal boundary layer on the duct walls. The disturbed thermal boundary layer is the main reason for the increments of the heat transfer potentiality and thermal performance. The better fluid blending is another cause for the growth of the heat transfer potentiality.

The maximum heat transfer potentiality is seen to be around 16.62 times above the general tested section for the type I V-Upstream arrangement at $a / H=0.075$. Types II and III give lower pressure loss than type I and also perform slightly lower heat transfer rate than type I. In the range investigation, the greatest TEF in the HED inserted with the DVR is found to be around 4.17, 4.13, and 4.04, for types I, II, and III, respectively. For suggestions, the optimum $a / H$ value for the HED fitted with the DVR is about 0.025 , while the optimum $b / H$ value is around $0.10-0.15$ when considered at TEF value.

The contour TEF of the HED inserted with the DVR at various $a / H, b / H$, and flow directions are plotted in Figures 25-27 for types I, II, and III, respectively. The TEF contours can help select the DVR structures and parameters for the HED.

The comparisons between the present results with the previous works are plotted in Figures 28(a)-28(c) in terms of $\mathrm{Nu} / \mathrm{Nu}_{0}, f / f_{0}$, and TEF, respectively. As the figures, the present vortex generator for all types gives greater TEF than the other kinds of the vortex generators [15, 22-27]. Additionally, the present vortex generator provides high heat transfer rate in the HED with a moderate pressure loss penalty.
The correlations of the $\mathrm{Nu} / \mathrm{Nu}_{0}$ and $f / f_{0}$ with various DVR types are written as equations (10)-(21). The variations of the present results with the correlation values are shown in Figures 29 and 30 for $\mathrm{Nu} / \mathrm{Nu}_{0}$ and $f / f_{0}$, respectively.

For type I, $a / H=0.025, b / H=0.10-0.20, \mathrm{Re}=100-2000$, $\mathrm{V}$-downstream:

$$
\begin{aligned}
\frac{\mathrm{Nu}}{\mathrm{Nu}_{0}} & =0.289 \operatorname{Re}^{0.688} \operatorname{Pr}^{0.4}\left(\frac{b}{H}\right)^{0.706}, \\
\frac{f}{f_{0}} & =3.373 \operatorname{Re}^{0.808}\left(\frac{b}{H}\right)^{2.000} .
\end{aligned}
$$

For type I, $a / H=0.025, b / H=0.10-0.20, \mathrm{Re}=100-2000$, $\mathrm{V}$-upstream:

$$
\begin{aligned}
\frac{\mathrm{Nu}}{\mathrm{Nu}_{0}} & =0.143 \operatorname{Re}^{0.730} \operatorname{Pr}^{0.4}\left(\frac{b}{H}\right)^{0.477}, \\
\frac{f}{f_{0}} & =2.284 \operatorname{Re}^{0.847}\left(\frac{b}{H}\right)^{1.883} .
\end{aligned}
$$

For type II, $a / H=0.025, \quad b / H=0.10-0.20$, $\mathrm{Re}=100-2000, \mathrm{~V}$-downstream:

$$
\begin{aligned}
\frac{\mathrm{Nu}}{\mathrm{Nu}_{0}} & =0.409 \operatorname{Re}^{0.666} \operatorname{Pr}^{0.4}\left(\frac{b}{H}\right)^{0.829}, \\
\frac{f}{f_{0}} & =3.451 \operatorname{Re}^{0.753}\left(\frac{b}{H}\right)^{1.883} .
\end{aligned}
$$

For type II, $a / H=0.025, \quad b / H=0.10-0.20$, $\operatorname{Re}=100-2000, \mathrm{~V}$-upstream:

$$
\begin{aligned}
\frac{\mathrm{Nu}}{\mathrm{Nu}_{0}} & =0.106 \operatorname{Re}^{0.689} \operatorname{Pr}^{0.4}\left(\frac{b}{H}\right)^{0.254}, \\
\frac{f}{f_{0}} & =2.226 \operatorname{Re}^{0.736}\left(\frac{b}{H}\right)^{1.588} .
\end{aligned}
$$

For type III, $a / H=0.025, \quad b / H=0.10-0.20$, $\mathrm{Re}=100-2000, \mathrm{~V}$-downstream:

$$
\begin{aligned}
\frac{\mathrm{Nu}}{\mathrm{Nu}_{0}} & =0.153 \operatorname{Re}^{0.711} \operatorname{Pr}^{0.4}\left(\frac{b}{H}\right)^{0.507}, \\
\frac{f}{f_{0}} & =2.041 \operatorname{Re}^{0.773}\left(\frac{b}{H}\right)^{1.710} .
\end{aligned}
$$


For type III, $a / H=0.025, \quad b / H=0.10-0.20$, $\mathrm{Re}=100-2000, \mathrm{~V}$-upstream:

$$
\begin{aligned}
\frac{\mathrm{Nu}}{\mathrm{Nu}_{0}} & =0.110 \operatorname{Re}^{0.732} \operatorname{Pr}^{0.4}\left(\frac{b}{H}\right)^{0.379}, \\
\frac{f}{f_{0}} & =1.849 \mathrm{Re}^{0.819}\left(\frac{b}{H}\right)^{1.730} .
\end{aligned}
$$

\section{Abbreviations}

$a$ : DVR height at the middle of the channel, $\mathrm{m}$

$b$ : DVR height on the upper-lower walls of the channel, $m$

$D_{h}$ : Hydraulic dimeter, $\mathrm{m}$

$f: \quad$ Friction factor

$H$ : $\quad$ Channel height

$h$ : Convective heat transfer coefficient, $\mathrm{W} \mathrm{m}^{-2} \mathrm{~K}^{-1}$

$k$ : Thermal conductivity, $\mathrm{W} \mathrm{m}^{-1} \mathrm{~K}^{-1}$

L: $\quad$ Periodic length of the physical model, $\mathrm{m}$

$\mathrm{Nu}$ : Nusselt number $\left(=h D_{h} / k\right)$

$P: \quad$ Pitch distance, $\mathrm{m}$

p: $\quad$ Static pressure, $\mathrm{Pa}$

Re: Reynolds number

T: $\quad$ Temperature, $\mathrm{K}$

$\bar{u}: \quad$ Mean velocity in channel, $\mathrm{m} \mathrm{s}^{-1}$

$\rho: \quad$ Density, $\mathrm{kg} \mathrm{m}^{-3}$

$\mu$ : Dynamic viscosity, $\mathrm{kg} \mathrm{m}^{-1} \mathrm{~s}^{-1}$

0: $\quad$ Plain duct

pp: Pumping power

DVR: Double V-ring

HED: Heat exchanger duct

TEF: Thermal efficiency factor $\left(=\left(\mathrm{Nu} / \mathrm{Nu}_{0}\right) /\left(f / f_{0}\right)^{1 / 3}\right)$.

\section{Data Availability}

No data were used to support this study.

\section{Conflicts of Interest}

The authors declare that there are no conflicts of interest regarding the publication of this article.

\section{Acknowledgments}

The authors would like to thank Assoc. Prof. Dr. Pongjet Promvonge for suggestions. This research was funded by King Mongkut's University of Technology North Bangkok (contract no. KMUTNB-65-BASIC-18).

\section{References}

[1] M. Bahiraei, N. Mazaheri, and H. Moayedi, "Employing $\mathrm{V}$-shaped ribs and nanofluid as two passive methods to improve second law characteristics of flow within a square channel: a two-phase approach," International Journal of Heat and Mass Transfer, vol. 151, Article ID 119419, 2020.

[2] M. Bahiraei, N. Mazaheri, Y. Hosseini, and H. Moayedi, “A two-phase simulation for analyzing thermohydraulic performance of $\mathrm{Cu}$-water nanofluid within a square channel enhanced with $90^{\circ} \mathrm{V}$-shaped ribs," International Journal of Heat and Mass Transfer, vol. 145, Article ID 118612, 2019.

[3] K. Matsubara, H. Ohta, and T. Ishino, "Direct simulation of inlet region heat transfer in a channel with repeated ribs under iso-thermal wall heating condition," International Journal of Thermal Sciences, vol. 154, Article ID 106408, 2020.

[4] F. Li, Q. Ma, G. Xin, J. Zhang, and X. Wang, "Heat transfer and flow characteristics of microchannels with solid and porous ribs," Applied Thermal Engineering, vol. 178, Article ID 115639, 2020.

[5] M. Bahiraei, A. Monavari, and H. Moayedi, "Second law assessment of nanofluid flow in a channel fitted with conical ribs for utilization in solar thermal applications: effect of nanoparticle shape," International Journal of Heat and Mass Transfer, vol. 151, Article ID 119387, 2020.

[6] G. Jiang, J. Gao, X. Shi, F. Li, and L. Xu, "Flow and heat transfer characteristics of the mist/steam two-phase flow cooling the rectangular channel with column-row-ribs," International Journal of Heat and Mass Transfer, vol. 156, Article ID 119737, 2020.

[7] W. Bai, D. Liang, W. Chen, and M. K. Chyu, "Investigation of ribs disturbed entrance effect of heat transfer and pressure drop in pin-fin array," Applied Thermal Engineering, vol. 162, Article ID 114214, 2019.

[8] Y. Li, Y. Rao, D. Wang, P. Zhang, and X. Wu, "Heat transfer and pressure loss of turbulent flow in channels with miniature structured ribs on one wall," International Journal of Heat and Mass Transfer, vol. 131, pp. 584-593, 2019.

[9] W. Bai, W. Chen, L. Yang, and M. K. Chyu, "Numerical investigation on heat transfer and pressure drop of pin-fin array under the influence of rib turbulators induced vortices," International Journal of Heat and Mass Transfer, vol. 129, pp. 735-745, 2019.

[10] P. Zhang, Y. Rao, Y. Xie, and M. Zhang, "Turbulent flow structure and heat transfer mechanisms over surface vortex structures of micro V-shaped ribs and dimples," International Journal of Heat and Mass Transfer, vol. 178, Article ID 121611, 2021.

[11] H. Xiao, Z. Liu, and W. Liu, "Turbulent heat transfer enhancement in the mini-channel by enhancing the original flow pattern with v-ribs," International Journal of Heat and Mass Transfer, vol. 163, Article ID 120378, 2020.

[12] P. K. Jain and A. Lanjewar, "Overview of V-RIB geometries in solar air heater and performance evaluation of a new V-RIB geometry," Renewable Energy, vol. 133, pp. 77-90, 2019.

[13] D. Jin, S. Quan, J. Zuo, and S. Xu, "Numerical investigation of heat transfer enhancement in a solar air heater roughened by multiple V-shaped ribs," Renewable Energy, vol. 134, pp. 78-88, 2019.

[14] R. Misra, J. Singh, S. K. Jain et al., "Prediction of behavior of triangular solar air heater duct using $\mathrm{V}$-down rib with multiple gaps and turbulence promoters as artificial roughness: a CFD analysis," International Journal of Heat and Mass Transfer, vol. 162, Article ID 120376, 2020.

[15] A. Boonloi and W. Jedsadaratanachai, "Numerical study on flow and heat transfer mechanisms in the heat exchanger channel with $\mathrm{V}$-orifice at various blockage ratios, gap spacing ratios, and flow directions," Modelling and Simulation in Engineering, vol. 2019, Article ID 8656435, 21 pages, 2019.

[16] D. Jin, J. Zuo, S. Quan, S. Xu, and H. Gao, “Thermohydraulic performance of solar air heater with staggered multiple V-shaped ribs on the absorber plate," Energy, vol. 127, pp. 68-77, 2017. 
[17] D. Jin, M. Zhang, P. Wang, and S. Xu, "Numerical investigation of heat transfer and fluid flow in a solar air heater duct with multi V-shaped ribs on the absorber plate," Energy, vol. 89, pp. 178-190, 2015.

[18] A. Kumar and M.-H. Kim, "Heat transfer and fluid flow characteristics in air duct with various V-pattern rib roughness on the heated plate: a comparative study," Energy, vol. 103 , pp. $75-85,2016$.

[19] S. Singh, S. Chander, and J. S. Saini, "Investigations on thermo-hydraulic performance due to flow-attack-angle in $\mathrm{V}$-down rib with gap in a rectangular duct of solar air heater," Applied Energy, vol. 97, pp. 907-912, 2012.

[20] S. V. Patankar, C. H. Liu, and E. M. Sparrow, "Fully developed flow and heat transfer in ducts having streamwise-periodic variations of cross-sectional area," Journal of Heat Transfer, vol. 99, no. 2, pp. 180-186, 1977.

[21] Y. A. Cengel and A. J. Ghajar, Heat and Mass Transfer: Fundamentals \& Applications, McGraw-Hill Education, New York, NY, USA, Fifth edition, 2015.

[22] A. Boonloi and W. Jedsadaratanachai, "Influence of ring size and location on flow topology, heat transfer structure and thermal efficiency in heat exchanger square channel placed with 30-degree inclined square ring," Frontiers in Heat and Mass Transfer, vol. 13, 2019.

[23] A. Boonloi and W. Jedsadaratanachai, "Flow and heat transfer characteristics or air in square channel heat exchanger with C-shaped baffle: a numerical study," Frontiers in Heat and Mass Transfer, vol. 13, 2019.

[24] A. Boonloi and W. Jedsadaratanachai, "The effects of gap spacing ratio on flow structure and heat transfer characteristic for the V-orifice in the square channel heat exchanger," Frontiers in Heat and Mass Transfer, vol. 12, 2019.

[25] A. Boonloi and W. Jedsadaratanachai, "Variations of heat transfer mechanism and flow structure in a heat exchanger tube fitted with 30 inclined ring," Advances in Mechanical Engineering, vol. 12, no. 3, pp. 1-16, 2020.

[26] W. Jedsadaratanachai and A. Boonloi, "3D numerical investigation on laminar forced convection and heat transfer in a circular tube inserted with right triangular wavy surfaces," Frontiers in Heat and Mass Transfer, vol. 8, 2017.

[27] A. Boonloi and W. Jedsadaratanachai, "Thermohydraulic performance improvement in heat exchanger square duct inserted with $45^{\circ}$ inclined square ring," Modelling and Simulation in Engineering, vol. 2020, Article ID 3862624, 22 pages, 2020 . 